\title{
Recent advances in biologically sensitive field-effect transistors
} (BioFETs)

\author{
Michael J. Schöning*ab and Arshak Poghossian ${ }^{b}$ \\ a University of Applied Sciences Aachen, Ginsterweg 1, D-52428 Jülich, Germany \\ ${ }^{b}$ Institute of Thin Films and Interfaces, Research Centre Juelich GmbH, D-52425 Jülich, \\ Germany.E-mail: m.j.schoening@fz-juelich.de.E-mail: a.poghossian@fz-juelich.de; \\ Fax: +49 2461612940; Tel: +492461612973
}

Received 8th May 2002, Accepted 6th August 2002

First published as an Advance Article on the web 16th August 2002

\section{Introduction \\ 2 BioFETs in general}

2.1 Biosensor definition and nomenclature

2.2 BioFET principle

3 Classification and advances in BioFETs

3.1 EnFET

3.2 ImmunoFET

3.3 GenFET

3.4 Cell-based BioFET

3.5 'Beetle/chip' FET

4 Conclusion and perspectives

5 Acknowledgements

6 References

\section{Introduction}

Research in the field of biosensors has enormously increased over the recent years. Since the development of the first biosensor by Clark in 1962, where an amperometric oxygen electrode was immobilised with an enzyme (glucose oxidase), ${ }^{1}$ many efforts have been invested to create functional hybrid systems. These functional hybrid systems often benefit from the coupling of the unique recognition and signal-amplification abilities of biological systems, that have been developed and optimised during millions of years of evolution, with an

Michael J. Schöning was born in Bruchsal, Germany, in 1962. He received his diploma in 1989 and Ph.D. in 1993, both in electrical engineering, from the Technical University (TH) Karlsruhe. In 1989 he joined the Institute of Radiochemistry at the Research Centre Karlsruhe, Germany. Since 1993 he has

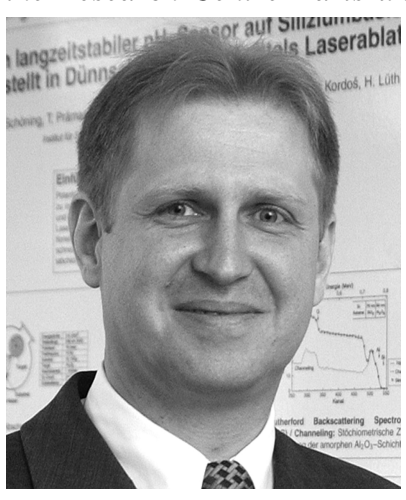
been with the Institute of Thin Films and Interfaces at the Research Centre Jülich, and since 1999 he has been a Professor of applied physics at the University of the Applied Sciences Aachen, Germany. His research interests include silicon-based chemical and biological sensors, thin film techniques, solid-state physics, semiconductor devices and microsystem technology. artificial man-made signal detection and amplification system. Thus, the combination of knowledge in bio- and electrochemistry, solid-state and surface physics, bioengineering, integrated circuit silicon technology and data processing offers the possibility of a new generation of highly specific, sensitive, selective and reliable micro (bio-)chemical sensors and sensor arrays. Moreover, the rapid development of silicon technology has stimulated the fabrication of miniaturised analytical systems such as $\mu$ TAS (micro total analysis system), 'lab on chip' sensors, electronic tongue devices and electronic noses. ${ }^{2-17}$

Among the variety of proposed concepts and different types of biosensors, the integration of biologically active materials together with an ISFET (ion-selective field-effect transistor) is one of the most attractive approaches. The ISFET was invented by Bergveld ${ }^{18}$ in 1970 and has been introduced as the first miniaturised silicon-based chemical sensor. In spite of distinct difficulties with regard to practical applications, the great interest in ISFET-based biosensors, so-called biologically modified field-effect transistors (BioFETs), has generated a great number of publications, a flow that shows no sign of diminishing. The reason therefore is that silicon-based fieldeffect devices are currently being the basic structural element in a new generation of micro biosensors; they provide a lot of potential advantages such as small size and weight, fast response, high reliability, low output impedance, the possibility of automatic packaging at wafer level, on-chip integration of biosensor arrays and a signal processing scheme with the future prospect of low-cost mass production of portable microanalysis systems; moreover, their possible field of applications reaches from medicine, biotechnology and environmental monitoring through food and drug industries to defence and security.

This paper gives a review of recent and significant advances in the research and development of BioFETs. In planing this review, we have chosen to focus mainly upon developments occurring during the last six years (from 1995 to the end of 2001). A computer search of the Science Citation Index has found that more than 400 publications concerning ISFETs and BioFETs have appeared from January 1995 to December 2001, indicating the intensity of research activities devoted to this important task. This review is in general limited to journal articles and usually does not include patents, conference proceedings, reports or $\mathrm{PhD}$ theses. Some references to important works reported prior to 1995 have also been added to provide additional source material.

The review is organised as follows: The principles of the ISFET and BioFET are described in section 2. Recent advances in the development of various types of BioFETs are reviewed in section 3. Here, some examples of current applications of BioFETs are presented, too. Concluding points and future prospects of BioFETs are discussed in section 4. 


\section{BioFETs in general}

\subsection{Biosensor definition and nomenclature}

A major driving force behind the significant increase of interest and research in biosensors has been the attraction to utilise the high specifity and sensitivity of biomolecules and living biological systems for sensor function: 'An electrochemical biosensor is a self-contained integrated device, which is capable of providing specific quantitative or semi-quantitative analytical information using a biological recognition element (biochemical receptor) which is retained in direct spatial contact with an electrochemical transduction element'.

This definition for an electrochemical biosensor was recently recommended by an IUPAC (International Union of Pure and Applied Chemistry) working group. ${ }^{19}$ Thus, biosensors represent functional hybrid systems, generally combining two basic components connected in series, namely a biological (molecular) recognition system and a physico-chemical transducer. The recognition system is often also called the bioreceptor, because in the natural chemical senses, the recognition phenomenon is performed by a chemoreceptive cell. The biosensor is usually constructed by attaching a biologically sensitive material to a suitable transducing system.

Different types of biologically sensitive materials of various complexity can be applied as recognition elements, including either biological molecular species [(e.g., enzymes, multienzyme systems, antibodies, antigens, proteins, or nucleic acids] or living biological systems (e.g., cells, plants, tissue slices, intact organs or whole organisms), which utilise biochemical mechanisms for recognition. The overall biological recognition system translates the information from the (bio)chemical domain, typically an analyte concentration, into a chemical or physical signal (bio-)chemical response. As a result of the specific molecular interaction, there is a change in one or more physico-chemical parameters. This change may produce ions, electrons, gasses, heat or light, etc. Then, these quantities are converted into a quantifiable signal-mostly to an electrical signal-by the transducer part, amplified, processed and displayed in a suitable form.

Depending upon the mechanism of (bio-)chemical interaction between the receptor part of the biosensor and the analyte, two basic types of biosensors can be distinguished: biocatalytic sensors and biocomplexing or bioaffinity sensors. Biocatalytic biosensors are the best known and studied biosensors since the pioneering work of Clark et al. ${ }^{1}$ Analyte concentrations detectable with biosensors can range from $10^{-7}$ $\mathrm{M}$ for biocatalytic sensors to trace concentrations of smaller than $10^{-15} \mathrm{M}$ for affinity sensors. ${ }^{20}$ Recently, a hybrid configuration of a biosensor which combines the attributes of both the high affinity binding and the amplification properties of an enzyme has also been suggested. ${ }^{20}$ Due to their simple principle of measurement and integratable signal processing on chip, biosensors that are based on electrochemical transducer principles are the most common sensor devices developed so far. According to the official nomenclature, recommended by IUPAC, ${ }^{19}$ electrochemical transducers include amperometric, potentiometric, conductometric, impedimetric and semiconductor field-effect principles.

To obtain a general overview of biosensors (not only electrochemically based, and specially FET-based sensors as in this article), some excellent books and reviews are available. ${ }^{19-56}$ For example, a general discussion of (bio-)chemical and molecular aspects of biosensors as well as a survey of the major types of biological molecules and systems (including antibodies, enzymes and whole cells) for biosensors are summarised in refs 19, 24, 37, 45 and 48. Transducer aspects of biosensors are discussed (e.g. in refs 19, 20, 35, 46 and 47). Biosensors and biochips in biological and medical diagnostics are emphasised, ${ }^{27,48}$ environmental applications of biosensors have been reviewed. ${ }^{47,49,50}$ A current development in biosensors for toxic materials of defence interest is surveyed. ${ }^{51}$ The design and placement of biosensors in microsystems as well as microfabrication technologies for biosensors that are fully compatible to microelectronic processing are discussed elsewhere. ${ }^{36,53,54}$ The major barriers to successfully commercialise biosensors for chemical processes, biotechnology and clinical diagnostics as well as economic problems that accompany the bringing onto the market have been critically assessed, (e.g. in refs 55 and 56). Recommended definitions and classifications of biosensors are discussed in ref. 19.

\subsection{BioFET principle}

In general, the ISFET represents the basic structural key element that is mostly used for BioFETs, even if its ionsensitive properties are not necessary for the signal transduction (for example, in affinity BioFETs or for the measurement of action potentials of living cells). BioFETs can be simply constructed from an ISFET by modifing the gate or coupling it with different biological recognition elements as schematically shown in Fig. 1. In these devices, the charge (or potential) effect is used to transduce the recognising phenomena. The most critical point in information transfer from the biological recognition part to the transducer part is the interface between these two domains. ${ }^{40}$ For a better understanding of the functional principle of a BioFET, which utilises the semiconductor field-effect as the coupling mechanism between the above mentioned two domains, the operating principle of the ISFET is first outlined in the following and chemico-physical phenomena underlying the ISFET transduction mechanism are discussed.

At present, there exist numerous different ISFET structures and processes for their fabrication, but the principle of using an electric field to create regions of excess charge in a semiconductor substrate in order to enhance or diminish the local conductivity is common to all of them. Reviews of various types of ISFETs are presented in refs 57-63. In addition, there are explicit recommendations that have been made about the terminology and conventions for ISFET devices. ${ }^{64}$

The functionality of an ISFET can be explained by comparing the sensor with a conventional IGFET (insulated-gate fieldeffect transistor) or MOSFET (metal-oxide-semiconductor field-effect transistor). The ISFET is then an IGFET, in which the metal gate is replaced by an ion-sensitive membrane, an electrolyte solution and a reference electrode. As one example,

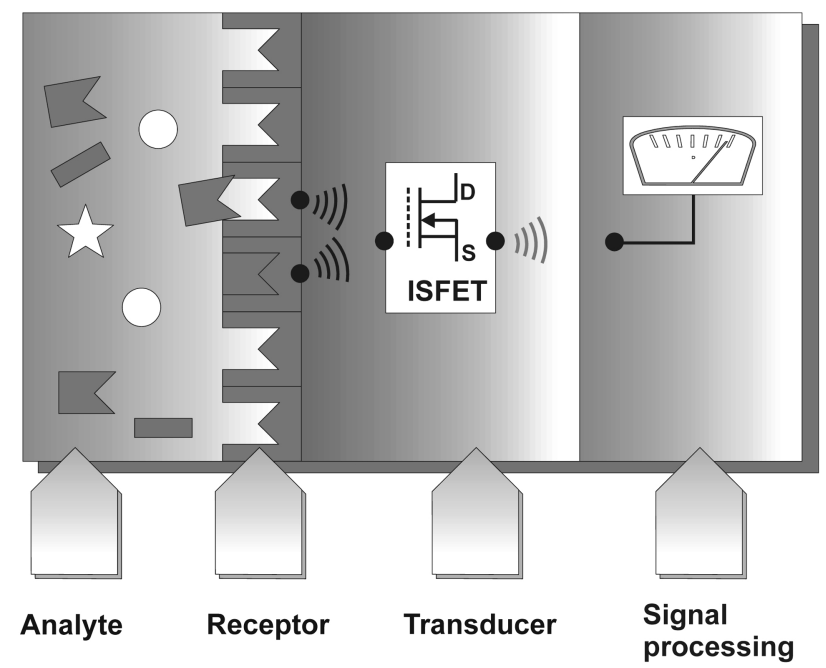

Fig. 1 Schematic set-up and functional principle of a (bio-)chemical sensor that is based on an ISFET, consisting of receptor, transducer and signal processing. 
a typical construction of an n-channel ISFET is schematically shown in Fig. 2. It consists of a p-type silicon substrate with two n-doped regions, source and drain, separated by a short channel that is covered by the gate insulator. Typically, the gate insulator is a $\mathrm{SiO}_{2}$ layer or a double layer insulator of $\mathrm{SiO}_{2}$ $\mathrm{Si}_{3} \mathrm{~N}_{4}, \mathrm{SiO}_{2}-\mathrm{Al}_{2} \mathrm{O}_{3}$ or $\mathrm{SiO}_{2}-\mathrm{Ta}_{2} \mathrm{O}_{5}$. The upper layer of these double insulator structures, i.e. $\mathrm{Si}_{3} \mathrm{~N}_{4}, \mathrm{Al}_{2} \mathrm{O}_{3}$ and $\mathrm{Ta}_{2} \mathrm{O}_{5}$, typically serve as sensitive materials for $\mathrm{pH}$-sensitive ISFETs. ISFETs that are selective towards other ions, so-called chemically-sensitive FETs (ChemFET) can be obtained by means of an additional surface modification of the gate insulator or by deposition of subsequent specific membranes on top of the gate insulator. Examples of such ChemFETs, for the determination of $\mathrm{K}^{+}, \mathrm{Ca}^{2+}, \mathrm{F}^{-}$, etc., are described elsewhere. ${ }^{57-61,65-73}$

For operating an ISFET, the gate voltage, $V_{\mathrm{G}}$, is applied by a reference electrode (e.g., $\mathrm{Ag} / \mathrm{AgCl}$ electrode), which is also responsible for fixing the potential of the test solution (analyte). When a sufficiently positive bias potential is applied to the gate (with respect to the bulk silicon substrate), an n-type inversion layer is induced in the channel between source and drain. The magnitude of the drain current, $I_{\mathrm{D}}$, will be determined by the effective electrical resistance of the surface inversion layer and the voltage, $V_{\mathrm{DS}}$, that is applied between source and drain. The mechanism of operation of the ISFET can be described by the processes (charge carrier distribution) which take place in each phase and at the interfaces. Correspondingly, the drain current of the ISFET, $I_{\mathrm{D}}$, can be deduced from that of an IGFET, by simply adding the potential drops at the additional interfaces: ${ }^{58-60}$

$$
\begin{gathered}
I_{\mathrm{D}}=\mu C_{\mathrm{i}}(W / L) V_{\mathrm{D}}\left[V_{\mathrm{G}}-\left(E_{\mathrm{ref}}-\varphi+\chi_{\mathrm{sol}}-\left(\phi_{\mathrm{Si}} / q\right)-\left(Q_{\mathrm{i}}+Q_{\mathrm{ss}}\right) /\right.\right. \\
\left.\left.C_{\mathrm{i}}-\left(Q_{\mathrm{B}} / C_{\mathrm{i}}\right)+2 \phi_{\mathrm{f}}\right)-0.5 V_{\mathrm{D}}\right]
\end{gathered}
$$

where $\mu$ is the electron mobility in the channel; $W$ and $L$ are the width and the length of channel, respectively; $E_{\mathrm{ref}}$ is the potential of the reference electrode; $\phi_{\mathrm{Si}}$ is the silicon electron work function; $q$ is the elementary charge; $C_{\mathrm{i}}$ is the capacitance of the gate insulator; $Q_{\mathrm{i}}, Q_{\mathrm{ss}}$ and $Q_{\mathrm{B}}$ are the charges located in the insulator, in the surface and interface states, and in the depletion region, respectively; $\chi_{\text {sol }}$ is the surface dipole potential of the solution; $\phi_{\mathrm{f}}$ is the potential difference between the Fermi level of doped and intrinsic silicon; $\varphi$ is the potential at the electrolyte-membrane interface that depends on the activitiy of ions in the analyte. The potential $\varphi$ can be calculated by the Nernst-Nikolsky equation or using a similar equation for ISFETs with a solution-insulator interface. In the case of a $\mathrm{pH}$ sensitive ISFET, the gate insulator (typically $\mathrm{Si}_{3} \mathrm{~N}_{4}, \mathrm{Al}_{2} \mathrm{O}_{3}$ or $\mathrm{Ta}_{2} \mathrm{O}_{5}$ ) senses the $\mathrm{H}^{+}$-ion concentration, generating an interface potential on the gate insulator. The $\mathrm{pH}$ response can be

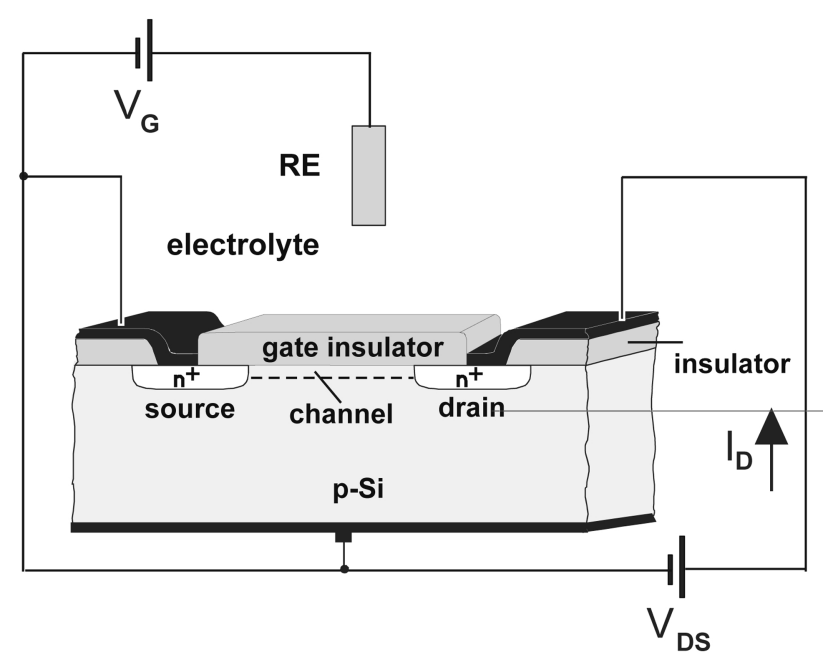

Fig. 2 Structure of an ISFET. RE, reference electrode; $V_{\mathrm{G}}$, gate voltage; $V_{\mathrm{DS}}$, drain-source voltage; $I_{\mathrm{D}}$, drain current. explained by the so-called site-binding theory. This model assumes that in contact with an aqueous solution, the surface of the gate insulator hydrolyses into ionisable sites (e.g., $\mathrm{OH}$ groups). These active sites are either able to bind or release hydrogen ions in a dynamic exchange process. Thus, their protonation state changes with the $\mathrm{pH}$ of the surrounding analyte. According to the site-binding model, the $\mathrm{pH}$ dependence of the interface potential analyte/ $\mathrm{pH}$-sensitive gate insulator, $\varphi$, is given by the following equation: $20,60,61$

$$
\varphi=2.3(k T / q)[\beta /(\beta+1)]\left(\mathrm{pH}_{\mathrm{pzc}}-\mathrm{pH}\right)
$$

where $\mathrm{pH}_{\mathrm{pzc}}$ (point of zero charge) is the $\mathrm{pH}$ value for which $\varphi$ $=0 ; k$ is the Boltzmann constant; $T$ is the absolute temperature; $\beta$ is a parameter which reflects the chemical sensitivity of the gate insulator and is dependent on the density of surface hydroxyl groups and the surface reactivity (for a detailed description of the ISFET operation principle, see refs 57-61, 74 and 75).

The resulting $\mathrm{pH}$-dependent electrical surface charge of the gate insulator leads to a modulation of the channel conductance and, consequently the drain current, $I_{\mathrm{D}}$, of the ISFET. Thus, by measuring changes in the drain current, the $\mathrm{pH}$ value of the test solution can be determined quantitatively. In practice, ISFETs are often operated in the so-called constant-charge (or constant drain current) mode. ${ }^{58,64,76}$ In the constant-charge mode, by setting the drain current at a fixed value using a feedback circuit, the voltage shift that results from the (bio-)chemical reaction can be recorded directly. The resulting sensor output signal is then proportional to the voltage shift. The arrangement in the constant-charge mode also allows a simultaneous multisensor characterisation by using only one common reference electrode.

Since the ISFET has been proved to be a sensor device that is very sensitive for any kind of electrical interaction at or nearby the gate insulator/electrolyte interface, in general, it will be clear that nearly each (bio-)chemical reaction leading to chemical or electrical changes at this interface can be measured by means of an ISFET coupled with a bioreceptor. Therefore, the following basic mechanisms of potential generation for BioFETs can be considered: (i) potential changes that are caused by a catalytic reaction product (e.g., between an enzyme and its substrate), this product can be detected by an ISFET; (ii) potential changes that are caused by surface polarisation effects or the change of dipole moments (e.g., antigen-antibody affinity reactions or DNA (deoxyribonucleic acid) hybridisation, in principle, under certain conditions an ISFET is able to detect the change of the electric field associated with affinity binding of biomolecules; (iii) potential changes that are coming from living biological systems as a result of more sophisticated (bio-)chemical processes (e.g., action potential of nerve cells).

Considering all these aspects, BioFETs can be classified according to the biorecognition element that is used for detection. Based on the hierarchy of biological complexity, they can be subdivided as depicted in Fig. 3: enzyme-modified FET (EnFET); immunologically modified FET (ImmunoFET); DNA-modified FET (DNA-FET or GenFET: gene-modified

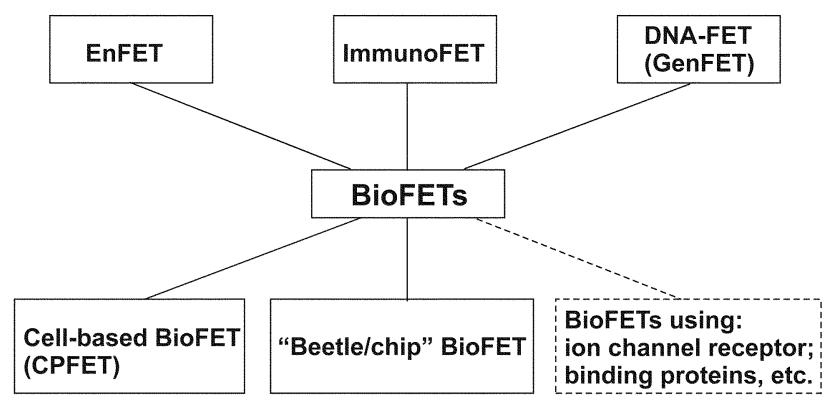

Fig. 3 Diagram of possible BioFET classification. 
FET); cell-based FET (or cell-potential FET (CPFET)); and 'beetle/chip' FET. In addition, 'artificial' BioFET-based biochips can be designed, where ion channel receptor, binding proteins, etc. are directly coupled to the microelectronic component. However, the development of this last group is still in progress.

Table 1 summarises major historical landmarks in the development of the different types of BioFETs. Since starting with the first concept of an ISFET in 1970 by Bergveld, it has taken over 25 years to advantageously utilise ISFETs for a direct DNA-hybridisation detection experiment.

\section{Classification and advances in BioFETs}

\subsection{EnFET}

Due to their specific binding capabilities as well as their catalytic activity, enzymes are often chosen as bioreceptors. The concept to design an EnFET, i.e. to combine enzymes with an ISFET was first proposed in 1976 by Janata and Moss ${ }^{77}$ and was realised in 1980 by Caras and Janata with a penicillin-sensitive biosensor. ${ }^{78}$ Later, a multitude of ISFETs were developed with the application of a wide variety of enzymes. ${ }^{57-61,84,85}$

EnFETs are usually constructed by immobilising an enzyme onto the gate insulator of an ISFET. The most critical point of the EnFET construction is the attachment of the enzyme or the enzyme-containing layer to the underlying inorganic gate insulator material of the FET. To immobilise enzymes, a number of methods are currently discussed, which include physical or chemical adsorption, entrapment within polymeric matrices, covalent binding, cross-linking by bi-functional crosslinking agents (mostly glutaraldehyde) and mixed physicochemical methods (entrapment and cross-linking). ${ }^{19,24,85-89}$

The simplest and most frequently used enzyme membrane deposition methods are the drop-on technique and the spin-

Table 1 Major historical landmarks in the development of BioFET devices

1970 Concept of an ISFET, first attempt to apply the ISFET in neurophysiological measurements ${ }^{18}$

1976 Concept of the first BioFET (EnFET) ${ }^{77}$

$1980 \quad$ First realised EnFET 78

1980 Concept of an ImmunoFET 79

1981 Coupling cells with a MOSFET ${ }^{80}$

1991 First neuron-transistor (or CPFET) 81

1997 'Beetle/chip' BioFET'82

1997 First experimental attempt of direct DNA-hybridisation detection 83 coating or the dip-coating of a mounted sensor chip into an enzyme solution. The very small amount of the sometimes expensive enzyme needed for the device fabrication, can also be considered to be an attractive feature in addition to other ISFETrelated advantages, like the small size (down to $\mu \mathrm{m}$ range), the small sample volume (down to nl range), etc. To improve the often quite poor adhesion between the transducer surface and the enzyme-containing layer, a prior surface silanisation is normally performed.

Generally, the working principle of an EnFET can be explained in the following way: during the enzymatic reaction of the enzyme with its substrate, either products are generated or reactants are consumed, and this concentration change can be monitored by the underlying ISFET. Hence, a corresponding change of the ISFET signal can be correlated with the original analyte concentration. As an example, Fig. 4 shows the structure and the functional principle of a penicillin-sensitive EnFET. The enzyme penicillinase catalyses the hydrolysis of penicillin to penicilloic acid yielding a local $\mathrm{pH}$ change near the gate region of the ISFET. Then, the output signal change will be determined by the amount of penicillin in the sample solution. Such an EnFET can be constructed, in principle, with any kind of enzyme. The nature, however, provides only a limited number of enzymes that are able to generate or consume electrochemically active species, in particular protons as required for EnFETs that are based on $\mathrm{pH}$-sensitive ISFETs.

A wide range of EnFETs differing in their sensor design or gate material, enzyme membrane composition or immobilisation method have been reported for the detection of the analytes glucose, urea, penicillin, ethanol, lactose, sucrose, maltose, ascorbic acid, lactate, acetylcholine, organophosphorus pesticides, formaldehyde, creatinine, etc. ${ }^{43,84-132}$ Some recently developed EnFETs are summarised in Table 2. With the exception of a few papers on urea-sensitive EnFET based on ammonia-108 or fluoride-sensitive ISFETs, ${ }^{128}$ most reported EnFETs are built-up of pH-sensitive ISFETs, in which the hydrogen ions are produced or consumed by the enzymatic reaction. The most popular enzymes for EnFETs are glucose oxidase, urease and penicillinase, because of their suitability as model systems for EnFET studies, and because of their important role for the detection of glucose, urea and penicillin in many fields of application. The corresponding enzymatic reactions are summarised in eqns (3)-(5):

$$
\text { penicillin }+\mathrm{H}_{2} \mathrm{O} \stackrel{\text { penicillinase }}{\longrightarrow} \text { penicilloic acid }+\mathrm{H}^{+}
$$

$$
\mathrm{NH}_{2}-\mathrm{CO}-\mathrm{NH}_{2} \text { (urea) }+\mathrm{H}_{2} \mathrm{O} \stackrel{\text { urease }}{\longrightarrow} 2 \mathrm{NH}_{4}^{+}+\mathrm{CO}_{2}+2 \mathrm{OH}^{-}
$$

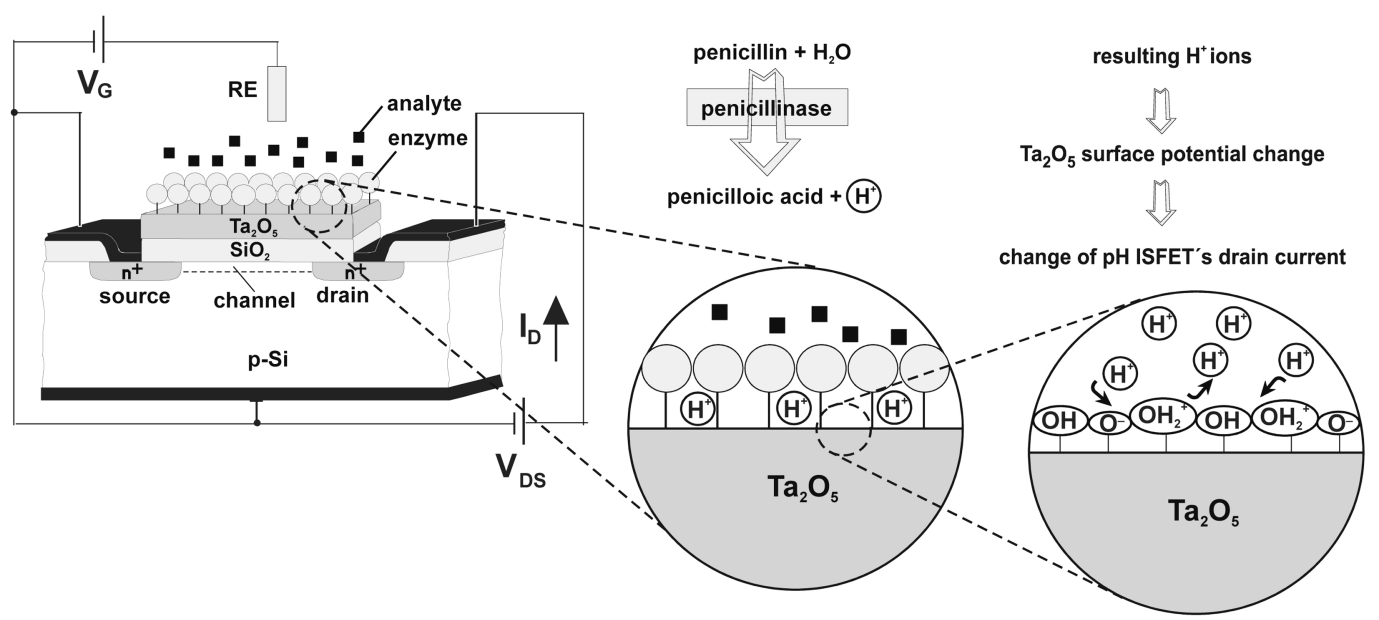

Fig. 4 Structure and principle of function of a penicillin-sensitive EnFET (PenFET). The enzyme penicillinase is immobilised on top of a pH-sensitive ISFET with $\mathrm{Ta}_{2} \mathrm{O}_{5}$ as $\mathrm{pH}$-sensitive gate insulator. 


$$
\begin{array}{ccc}
\beta \text { - D - glucose }+\mathrm{H}_{2} \mathrm{O}+\mathrm{O}_{2} & \stackrel{\text { glucose oxidase }}{\longrightarrow} \\
\text { gluconic acid } & + & \mathrm{H}_{2} \mathrm{O}_{2} \\
\downarrow & \downarrow \quad 0.65 \mathrm{~V} \text { vs. } \mathrm{Ag} / \mathrm{AgCl}
\end{array}
$$

In practice, for exact measurement of the test sample, a $\mathrm{pH}$ ISFET/EnFET differential arrangement (Fig. 5) is often employed (see e.g., refs. 84,111 and 114), where the pH ISFET acts as a reference system and is assembled in the same way as the EnFET, but it contains a blank enzyme-free membrane. Differential mode measurements have many advantages compared to single EnFET measurements and allow an automatic compensation of effects that are caused by some disturbing factors such as $\mathrm{pH}$ variation of the bulk solution, temperature variation, drift of the sensor output signal with the time, etc. Thus, the differential output signal only depends on the concentration of the analyte to be necessarily detected. Moreover, in this case a strongly stable reference electrode is not required. A gold or platinum metal can be used as a common 'pseudo' reference electrode, which can be simply integrated onto the FET chip yielding a fully miniaturised biosensor.

Intensive efforts during recent years have focused on the improvement of the working characteristics of EnFETs and on solving problems, which actually prevent their commercial development and limit the field of their practical use. These problems include limitations related to the operating principle

\begin{tabular}{|c|c|}
\hline Analyte & Enzyme system \\
\hline \multirow{3}{*}{ Glucose } & Glucose oxidase $\mathrm{e}^{90-98,100,129,130}$ \\
\hline & Glucose oxidase $/ \mathrm{MnO}_{2}$ powder ${ }^{99}$ \\
\hline & Glucose dehydrogenase ${ }^{101}$ \\
\hline \multirow[t]{3}{*}{ Urea } & Urease $^{87,95,101-108}$ \\
\hline & Penicillin penicillinase $\mathrm{e}^{109-113,115}$ \\
\hline & Penicillin $G$ acylase ${ }^{114}$ \\
\hline \multirow[t]{2}{*}{ Sucrose } & Invertase/mutarotase/glucose oxidase $\mathrm{e}^{92}$ \\
\hline & Invertase/glucose dehydrogenase 101,117 \\
\hline Maltose & Maltase/glucose dehydrogenase $\mathrm{e}^{101}$ \\
\hline Ethanol & $\begin{array}{l}\text { Alcoholdehydrogenase/aldehyde } \\
\text { dehydrogenase }\end{array}$ \\
\hline \multirow[t]{2}{*}{ Lactose } & $\begin{array}{l}\beta \text {-Galactosidase/glucose } \\
\text { dehydrogenase }^{116}\end{array}$ \\
\hline & $\begin{array}{l}\beta \text {-Galactosidase/galactose } \\
\text { dehydrogenase }\end{array}$ \\
\hline Ascorbic acid & Peroxidase $\mathrm{e}^{98,118}$ \\
\hline Creatinine & Creatinine deiminase ${ }^{126}$ \\
\hline Formaldehyde & Alcohol oxidase 124,125 \\
\hline Acetylcholine & Acetylcholinesterase 95,119 \\
\hline $\begin{array}{l}\text { Organophosphate compound } \\
\text { (paraoxon) }\end{array}$ & Organophosphate hydrolase ${ }^{122}$ \\
\hline $\begin{array}{l}\text { Fluorine-containing } \\
\text { organophosphates }\end{array}$ & Organophophorus acid anhydrolase ${ }^{123}$ \\
\hline
\end{tabular}
of EnFETs, the semiconductor device itself as well as the

Table 2 Recently developed EnFETs including the enzyme system used and the analyte to be detected

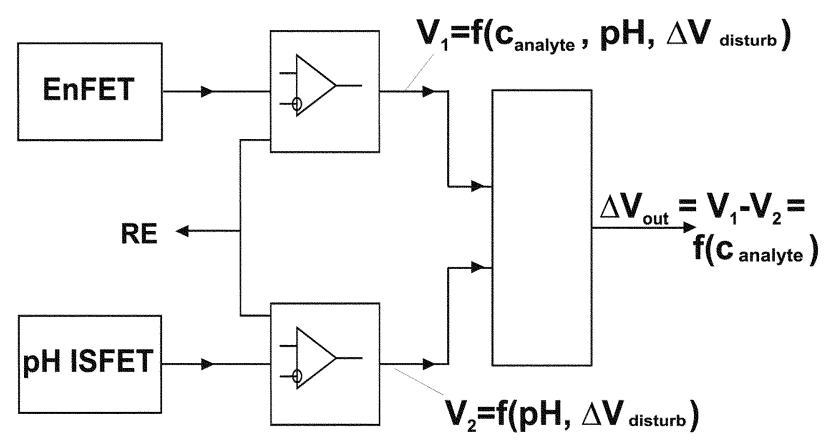

Fig. 5 pH ISFET/EnFET differential arrangement. The pH ISFET acts as 'reference' system; it is buit-up in the same way as the EnFET but without immobilised enzyme membrane. following technological factors: (i) the dependence of the sensor response on buffer capacity, ionic strength and $\mathrm{pH}$ of the test sample; (ii) the higher value of detection limit, restricted dynamic range and non-linearity; (iii) the relatively slow response and recovery times; (iv) the operating and storage stability, the light sensitivity as well as reproducibility; (v) the dependence on enzyme immobilisation and deposition methods; and (vi) the incompatibility of most used enzymecontaining layer deposition and patterning methods with silicon integrated circuit technology.

Recently, a number of technological solutions have been proposed and tested to solve these drawbacks and to improve the working characteristics of EnFETs. Some of these problems can be removed or at least reduced by applying additional charged polymeric membranes (e.g., Nafion or poly(4-vinylpyridine-co-styrene)) on top of the enzyme membrane, which control the substrate and product diffusion. $93,100,103,104,113,115$ Such approaches have been used in order to reduce the influence of the buffer and salt concentration on the sensor response, to extend the dynamic range and to increase the sensitivity of glucose- ${ }^{93}$ and urea-sensitive ${ }^{103}$ EnFETs. However, this concept is not universal. For instance, no improvement has been achieved in the case of a penicillin-sensitive EnFET.113

Another design was introduced, ${ }^{133}$ where a $\mathrm{pH}$-static ureasensitive EnFET was developed by keeping the $\mathrm{pH}$ of the enzyme membrane at a constant, predetermined value using an in situ coulometric titration of the enzymatic reaction products, namely the $\mathrm{H}^{+}$ions. In this case, the EnFET is able to linearly measure the substrate concentration over an extended concentration range, independent of the buffer capacity of the sample solution.

An alternative principle has been suggested, ${ }^{90,92}$ where an additional $\mathrm{Pt}$ electrode is deposited on the gate region of a glucose-sensitive EnFET; the function of the Pt electrode is to electrolyse hydrogen peroxide (i.e., the by-product of the glucose oxidation reaction) and generate two additional hydrogen ions (see eqn. (5)). The sensitivity, dynamic range and response time of the biosensor could be significiantly improved in this way. Recently, the authors have also demonstrated an allsolid-type ISFET glucose sensor with an integrated $\mathrm{Ag} / \mathrm{AgCl}$ reference electrode on the same chip. ${ }^{91}$

With the same background, a further EnFET 99 utilises a glucose oxidase membrane doped with manganese dioxide $\left(\mathrm{MnO}_{2}\right)$ powder that catalyses hydrogen peroxide. As a result, the additional product oxygen is produced, which can be recycled for the glucose oxidation reaction. In this way, the dynamic range of glucose measurement was extended up to 20 $\mathrm{mM}$. Hence, the developed EnFET with a high upper detection limit can be in principle applied to the detection of glucose in undiluted blood samples (the glucose concentration in human blood is normally about $5 \mathrm{mM}$, reaching $20 \mathrm{mM}$ and more for diabetics).

The concept of in situ electrochemical generation of ions was used 96,97 in order to improve the recovery time of a glucosesensitive EnFET. After the response of the sensor, hydroxyl ions $\left(\mathrm{OH}^{-}\right)$are generated in the enzyme membrane by applying a reduction potential to an additional $\mathrm{Pt}$ electrode. As a result, the recovery time of the presented glucose-sensitive EnFET was reduced to less than two minutes.

To reduce the response time of BioFETs in ${ }^{95}$ different EnFETs modified with a monolayer/multilayer enzyme have been developed. The major advantage of these enzyme-thinlayered sensors is their fast response time (e.g., ca. $10 \mathrm{~s}$ for the urea-sensitive EnFET). This advantage over traditional thickpolymer-based EnFETs results from the low diffusion barrier for the substrate penetration to the biocatalytically active sites. Disadvantages of the monolayer-modified EnFETs are the relatively short lifetime and low stability.

A highly sensitive, low detection limit and long lifetime penicillin-sensitive EnFET was developed ${ }^{109-112}$ by simple 
adsorptive immobilisation of the enzyme penicillinase on a $\mathrm{Ta}_{2} \mathrm{O}_{5}$-gate ISFET. As the EnFET works on the principle of $\mathrm{pH}$ change caused by an enzymatic reaction, the sensitivity, detection limit and linear range of the calibration curve of EnFETs are mostly affected by $\mathrm{pH}$, buffer solution and ion concentration of the buffer solution. Higher penicillin sensitivity (about $120 \mathrm{mV} \mathrm{mM}^{-1}$ ) and an extremely low detection limit $(5 \mu \mathrm{M})$ of an EnFET described in ${ }^{109-112}$ was achieved by using an optimised low capacity polymix buffer solution.

A chemical grafting of enzyme molecules directly on the ionsensitive gate of an ISFET has been realised in ${ }^{108}$ for a ureasensitive EnFET. The influence of different technological procedures of the enzyme immobilisation on the characteristics of glucose-, urea- and cholinesterase-sensitive EnFETs have been investigated. ${ }^{88}$

A number of attempts have been made to integrate several EnFETs on a single chip or in a hybrid module. The main goal of all these attempts is to obtain a miniature multiple EnFET array that permits the measurements of several analyte concentrations sequentially or simultaneously. A multi-enzyme sensor for the determination of glucose, ascorbic and citric acid by two EnFETs was developed. ${ }^{98}$ Moreover, an EnFET array for the detection of four analytes (urea, glucose, acetylcholine and $\mathrm{N}$ acetyl-L-tyrosine ethyl ester) has been reported. ${ }^{95} \mathrm{~A}$ multi EnFET array integrated in a commercial FIA (flow-injection analysis) system has been developed;101 this array enables the simultaneous monitoring of glucose, maltose, sucrose, lactose, ethanol and urea during the cultivation process in biotechnology. However, the main problem with a multi EnFET array is possible cross-sensitivity. Because of the close distance between the enzyme membranes and the gates of the EnFETs in an array, the local variations of the $\mathrm{pH}$ value caused by the enzymatic reaction in a particular enzyme membrane can influence the reaction rate in another membrane (different enzymes usually have different $\mathrm{pH}$ optima) and thus, can influence the output signal of another EnFET within the array. This cross-sensitivity can be eliminated, for example, by means of an optimisation of the $\mathrm{pH}$ value, favourable for all applied enzymes, ${ }^{117}$ or by the use of an FIA system under an automatic control with a proper carrier flow as well as a proper sequence of the enzyme membranes. ${ }^{101}$

The existing methods for depositing enzyme-containing layers on the FET transducers are mostly based on manual techniques, which are relatively simple but time-consuming, only poorly reproducible and incompatible with modern integrated circuit technology. A basic form of EnFET, i.e. the $\mathrm{pH}$ ISFET, is today a commercial reality ( $\mathrm{pH}$ ISFETs are available from Orion, Beckman, Sentron, Honeyweel, ChemFET Corporation, etc. $)^{134}$ and produced by silicon integrated technology. Therefore, for the fabrication of truly inexpensive and thus disposable biosensors, it is of great interest to manufacture the enzyme-containing layers also in batch processes. Besides, multi-biosensors can be made by using different masks. Recently, a number of fabrication techniques for wafer-level deposition and patterning of enzyme-containing layers have been developed. Possible methods include the utilisation of photocurable polymers such as polyacrylamide ${ }^{105}$ or polyurethane acrylate, ${ }^{87,106}$ the lift-off technique, ${ }^{130}$ the Langmuir-Blodgett technique and the ink-jet nozzle technique for the localised deposition of individual enzyme membranes (see also refs 39 and 84). A microcontact printing technique ${ }^{135}$ can also be advantageous for the deposition and patterning of protein layers. These techniques permit the integration of the enzymatic membrane fabrication into the whole ISFET fabrication process.

Another important aspect with regard to commercialisation of EnFETs, is their encapsulation and packaging. Since BioFETs, in particular EnFETs, work in electrolyte solution, they require encapsulation only on selected parts of the device, like bonding pads, bonding wires and silicon substrate, whereas the sensitive part of the biosensors have to be left exposed to the environment that they sense. However, this encapsulation and packaging of EnFETs is exactly one of the most important and critical steps in the complete fabrication process. For commercial realisation, a full automatisation of the fabrication process is necessary. It is thus very important to develop a wafer-level encapsulation procedure that is compatible with conventional silicon technology. Early proposed approaches on this subject such as the use of anisotropic etching of $\mathrm{Si}$, the $\mathrm{Si}$ on sapphire structure, the rear-side contact-type ISFET, the rear-side gatetype ISFET, etc., are reviewed in ref. 63. Recently, a wafer-level packaging technique for ISFET-based biosensors ( $\mathrm{pH}$ ISFET and urea-sensitive EnFET) using a photocurable polyurethane encapsulant formulation and a special thick film photolithography approach has been realised in ref. 106. A novel three-dimensional mesa ISFET was developed ${ }^{136}$ which simplifies the encapsulation procedure and thus enables flat packaging. A new method of fabrication of BioFETs based on an $\mathrm{Si}-\mathrm{SiO}_{2}-\mathrm{Si}$ structure was demonstrated by constructing a glucose-sensitive EnFET. ${ }^{94}$ The required encapsulation of the side walls and rear-side of the EnFET chip were carried out during the ISFET fabrication process using $\mathrm{SiO}_{2}, \mathrm{Si}_{3} \mathrm{~N}_{4}$ or $\mathrm{Ta}_{2} \mathrm{O}_{5}$ films. Another concept to guarantee the solutionresistant encapsulation has been proposed ${ }^{119}$ where an extended gate (or separate gate) EnFET was built-up; this biosensor is able to detect acetylcholine by using the enzyme acetylcholinesterase. This structure has a lot of benefits such as being simple in fabricating and packaging, being insensitive towards light and being flexibile in the shape of the extended gate area. This biosensor might be practical for application in disposable multi-biosensors in the near future. Nevertheless, at present, there is no unique and generally applicable encapsulation and packaging method common for all BioFETs. In most cases so far, encapsulation and packaging are still done by hand.

With regard to possible practical applications, EnFETs were utilised for the determination of glucose in blood serum ${ }^{100}$ and urine, ${ }^{94}$ urea in blood serum ${ }^{102,104,107}$ and in hemodialysis fluids. ${ }^{102}$ Moreover, an EnFET-based transcutaneous blood glucose monitoring system has been realised and applied to diabetic patients. ${ }^{129,130}$ The tested results could demonstrate the feasibility of the developed biosensor system for individual patients with various diabetic histories or diabetic complications. Another EnFET-based sensor system for the determination of creatinine in hemodialysis solutions and in serum of renal failure patients was realised in ref. 126. As a further approach in ref. 118 an ascorbic acid-sensitive EnFET for the vitamin $\mathrm{C}$ determination in beverages is presented. Glucose, maltose, sucrose, lactose, ethanol and urea concentrations were monitored simultaneously during the cultivation of Escherichia coli and Saccharomyces cerevisiae by means of an EnFET array, which has been integrated in a commercial flow-injection system. ${ }^{101}$ Penicillin-sensitive EnFETs were applied, namely for the determination of penicillin $\mathrm{G}$ in penicillin fermentation broths. ${ }^{114}$

Although EnFETs have a long history and much effort and investment have been put into them, the transfer of EnFETs from scientific laboratories to real life remains rather slow. Up to now, no EnFET has been really commercialised for a wider range of applications. Thus, a lot of work still remains to be done to achieve a successful commercial product.

\subsection{ImmunoFET}

The high recognition ability of biological molecules is best typified by an antibody-antigen interaction. An antibody is a complex biomolecule consisting of hundreds of individual amino acids arranged in a highly ordered sequence; the antigen can be any macromolecule against which the antibody has been 
generated as a result of the defensive mechanism of the organism known as the immune response. Proteins with molecular weights greater than 5000 Daltons are generally immunogenic, ${ }^{48}$ i.e. susceptible to being recognised and bound by antibody with extremely high specificity. A minor chemical modification of the molecular structure of the antigen can dramatically lower its affinity towards the original antibody. Thus, immunosensors may be useful for quantifying how well the human immune system is functioning, and consequently they can serve as excellent clinical diagnostic tools.

The possibility to directly monitor antibody-antigen interactions, finding thus a simplified alternative to classical immunoassays, has attracted many attempts to develop biosensors in which the actual recognition takes place in a layer of antibodies at the surface of the sensor (FET). Therefore, in this review, attention will mostly be focused on the direct label-free ImmunoFET. For indirect ImmunoFETs as well as for ImmunoFET-based immunoenzymatic assays, where label molecules such as enzymes are linked to antibodies or antigens in order to carry detectable species to the sensor, see refs 137-142. In addition, for the general aspects of immunosensors and different engineering approaches see reviews refs 143-145.

A concept of direct immunosensing by an ISFET was introduced by Schenck in $1978 .{ }^{79} \mathrm{In}$ an ImmunoFET, which is shown schematically in Fig. 6, the gate is modified by immobilising antibodies or antigens (often in a membrane). Since a FET basically represents a surface-charge measuring device, and since antibodies and antigens (or more generally, proteins) are mostly electrically charged molecules, it was expected that the formation of an antibody-antigen complex on the gate of an ISFET would lead to a detectable change in the charge distribution and thus, directly modulate the drain current of the ISFET. In this way, a unique possibility of direct detection of immunological reactions by means of an ImmunoFET could be obtained. Many research efforts have been expended to realise this idea, however, the results obtained were unsatisfactory due to fundamental limitations. It has been intensively debated whether or not it would be possible to measure the charge redistribution that is characteristic for an antibody-antigen affinity binding with an ISFET. ${ }^{59,146-148}$ In principle, under ideal conditions the ImmunoFET is at least theoretically capable of measuring the concentration of immunomolecules with a very low detection limit and a wide concentration range of $10^{-7}-10^{-11} \mathrm{M}$ with about a $10 \mathrm{mV}$ response signal. ${ }^{59}$ Ideal conditions that are required in this coherence are: a truly capacitive interface at which the immunological binding sites can be immobilised; a nearly complete antibody coverage; highly charged antigens and a very low ionic strength. However, the principal practical problem is to transduce the molecular recognition action between an antibody and an antigen into a measurable signal. It is obvious that the potential (charge) distribution in the immediate vicinity

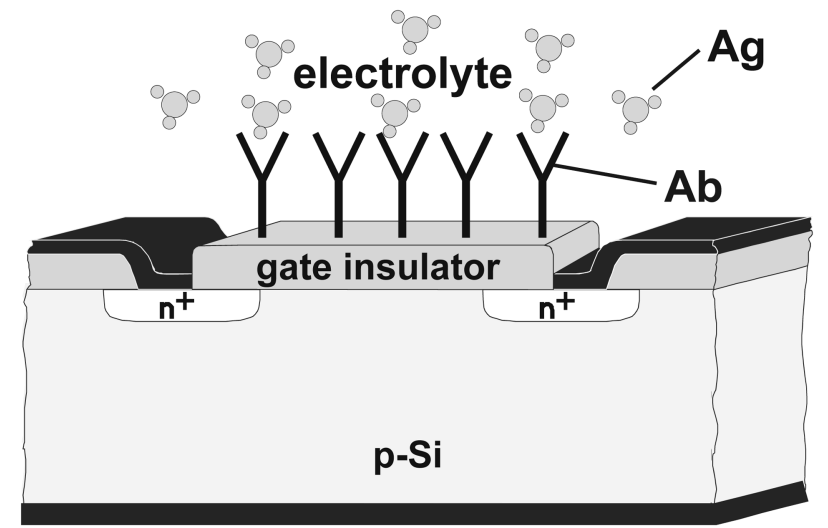

Fig. 6 Schematic structure of an ImmunoFET with immobilised antibody (Ab) molecules. Ag, antigen molecules. of the interface plays a critical role in transferring an immunological signal to the ISFET.

Fig. 7 illustrates this situation. The potential distribution at the electrolyte-ImmunoFET interface with immobilised antibody molecules in high and low ionic strength solutions is shown schematically. It can be seen that only potential (or charge density) changes which occur within the order of the Debye length $\delta$ can be detected. Coupling of proteins to the surface of an ISFET within this distance has not been, however, a realistic possibility so far. ${ }^{148}$ Dimensions of macromolecules, like antibodies, are much longer $(c a .10 \mathrm{~nm})$ than those of the double layer ( $c a .1 \mathrm{~nm}$ in a physiological-type solution) at the electrolyte-insulator interface. As a consequence, in such a case the protein charge will be at a distance greater from the surface than the Debye length [Fig. 7(a)] and thus, will be shielded by counter ions. The certain overlapping of potentials [Fig. 7(b)], consequently a measurable effect with an ImmunoFET can only be obtained in solutions with low ionic strength $\left(<10^{-2}-10^{-3}\right.$ M).

An extensive critical evaluation of early works related to potentiometric immunosensors, in particular ImmunoFETs, is given in ref. 148 where the Donnan theory is used as a possible explanation for the observed results. Nowadays, it is generally accepted that screening of protein charges by small inorganic counter ions present in the solution results in macroscopically uncharged layers and prevents successful measurements of immunospecies. ${ }^{40}$

To overcome the above described difficulties of a direct detection of immunological reaction with ISFETs in a static measurement set-up, some dynamic measurement methods have been developed. 40 The net charge density in a protein layer immobilised in a membrane on an ISFET can be measured by exposing the membrane to a stepwise (ion-step) change in the electrolyte concentration. The 'ion-step' method was used to determine e.g. the heparin concentration with a $\mathrm{Ta}_{2} \mathrm{O}_{5}$-gate ISFET possessing an immobilised monolayer of protamine as an affinity ligand for heparin. ${ }^{149}$ Alternatively, the acid-base properties of proteins can be used as transducing parameters for ISFET-based immunosensors. ${ }^{150-152}$ If the affinity binding of a substance to a protein, immobilised in a membrane, results in a significant change of this behaviour, the detection of this change enables the construction of a new type of biosensor. The required measurement principles for this can rely on coulometric titrant generation, $\mathrm{pH}$-step titration and ion-step meth-

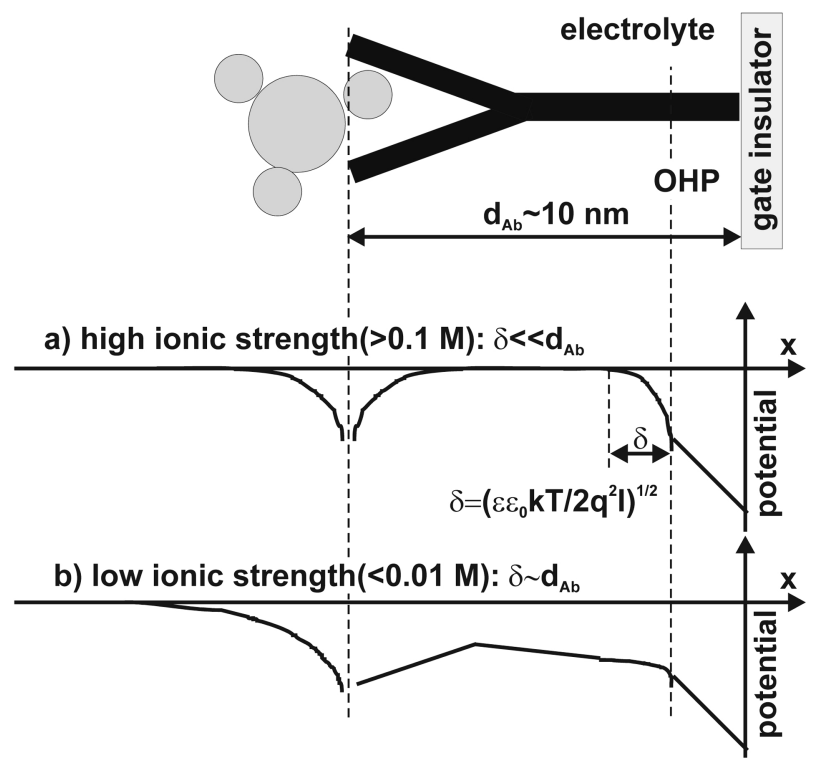

Fig. 7 Schematic presentation of the potential distribution in an electrolyte/ImmunoFET structure as a function of the distance from the gate-insulator surface by high (a) and low (b) ionic strength. $\delta$, Debye length; $d_{\mathrm{Ab}}$, dimension of macromolecule (e.g., antibody). 
ods. ${ }^{151,152}$ As an example, the lysozyme concentration was measured by means of the $\mathrm{pH}$-step method in the concentration range from $3 \times 10^{-7}$ to $3 \times 10^{-4} \mathrm{M} .{ }^{151}$ Another approach is proposed 153,154 where the authors have demonstrated the feasibility of an ISFET-based immunosensor using the streaming potential (or zeta potential) measurement set-up.

A further approach is the employment of an ImmunoFET in an impedance-measurement configuration. In contrast to the former described direct voltage or direct current behaviour, respectively, the alternating current behaviour of an ISFET is much more influenced by the presence of an additional protein layer. ${ }^{155}$ Recently, the impedance spectroscopy method was used $^{156}$ to characterise immobilised protein layers on the gate of an ISFET and to detect the antigen-antibody binding reaction. The output signal of the developed dinitrophenyl antigenmodified ISFET at different concentrations of dinitrophehyl antibody have been measured as a frequency of $30 \mathrm{kHz}$. The sensitivity of about $22 \mathrm{mV}$ per decade was achieved in the linear range of antibody concentration from 1 to $100 \mathrm{ng} \mathrm{ml}^{-1}$.

Generally, it can be concluded that, in fact, the practical development of an ImmunoFET for the direct detection of immunological molecules appears to be more difficult than originally expected. The theoretical basis of the sometimes observed results still remains unclear. Much more theoretical (modelling) and experimental research have to be done in order to understand and interpret ImmunoFET measurements.

\subsection{GenFET}

In recent years, the rapid progress of the Human Genome Project has stimulated the development of so-called genosensors and DNA chip technology, which draw upon the building blocks of genetics, i.e. DNA and RNA (ribonucleic acid), as biorecognition elements. These devices offer a new approach for fast, simple and inexpensive analysis of nucleic acid samples with tremendous possibilities for practical applications in various fields such as the diagnosis of genetic diseases, the detection of infectious agents, drug screening, etc. For instance, currently about 400 diseases are diagnosable by molecular analysis of nucleic acids, and this number is increasing daily. ${ }^{157}$

Most of the DNA detection techniques are based on a DNA hybridisation process. In DNA hybridisation, the target (unknown single-stranded DNA (ssDNA)) is identified by a probe molecule with which it forms a double-stranded (dsDNA) helix structure with its complementary nucleic acid with high efficiency and specificity in the presence of a mixture of many different non-complementary nucleic acids. The unique complementary nature of the base pairing, i.e. adenine-thymine and cytosine-guanine, is the basis for the extremely high specificity of the biorecognition process. In the literature, different approaches for genosensors using different types of transducer principles, like cyclic voltammetry, chronopotentiometry, capacitive, impedimetric and semiconductor field-effect principles, etc., have been described. For details, readers are referred to reviews of recent efforts in the field of genosensors and DNA chips. ${ }^{157-164}$

A DNA-modified FET or GenFET, schematically shown in Fig. 8, can also be very useful for hybridisation detection. A GenFET can be obtained by immobilising well-defined sequences of ssDNA onto a transducer, which converts the specific recognition process of two DNA single strands through the hybridisation event into a measurable signal. The inherent miniaturisation of such devices and their compatibility with advanced microfabrication technology can make them very attractive for DNA diagnostics. Unfortunately, there are only a few publications that are related to ISFETs for DNA sensing. For example, ISFETs have been used for the sequence-selective detection of PCR (polymerase chain reaction) products. ${ }^{165-167}$ However, for the development of fast, single, inexpensive and disposable genosensors, direct label-free methods of hybridisation detection are needed. To our knowledge, a first and only successful attempt in the direct detection of a hybridisation event with a GenFET was reported by Souteyrand et al. in 1997.83 Non-complex synthetic single strands of homo-oligomers have been chosen as a model system to demonstrate the feasibility of using an ISFET for the detection of a DNA hybridisation event. Therefore, homo-oligomers either 20 $(\mathrm{dT})_{20}$ or of the order of 1000 thymine bases (poly(dT)) were immobilised on the previously modified $\mathrm{SiO}_{2}$-gate of an ISFET. To detect the hybridisation process in real time, in situ measurements were performed by adding a certain volume of the complementary DNA (synthetic homo-oligomer single strands $(\mathrm{dA})_{18}$ or poly(dA) ( 1000 bases $)$ ) solution directly to the buffered electrolyte. The denaturisation was performed by immersing the sensor in boiling, deionised water for $0.5 \mathrm{~h}$.

Fig. 9 shows the response of a GenFET to successive additions of poly $(\mathrm{dA})$. A direct dependence on the quantity of poly(dA) added was achieved. The authors conclude that the observed changes of the gate voltage of the GenFET during the hybridisation process can be seen as a result of the surface charge change. These results are in good agreement with flatband potential shifts measured with DNA-modified EIS (electrolyte-insulator-semiconductor) structures. ${ }^{168-170}$ At the same time, there were discussions ${ }^{171}$ that EIS-based genosensors consisting of a $\mathrm{Si}-\mathrm{SiO}_{2}-\mathrm{Si}_{3} \mathrm{~N}_{4}$ structure, were not sufficiently sensitive enough to detect hybridisation events. The hybridisation detection was only possible with mechanically degraded EIS structures, i.e., a part of the dielectric area was removed by scratching it with a diamond scribe.

Today, there are still insufficient experimental results on the basis of GenFETs for clearly understand their functioning. Let us believe that this situation will improve in the near future and much effort will be directed towards new experiments with GenFETs and the development of theoretical models, which can

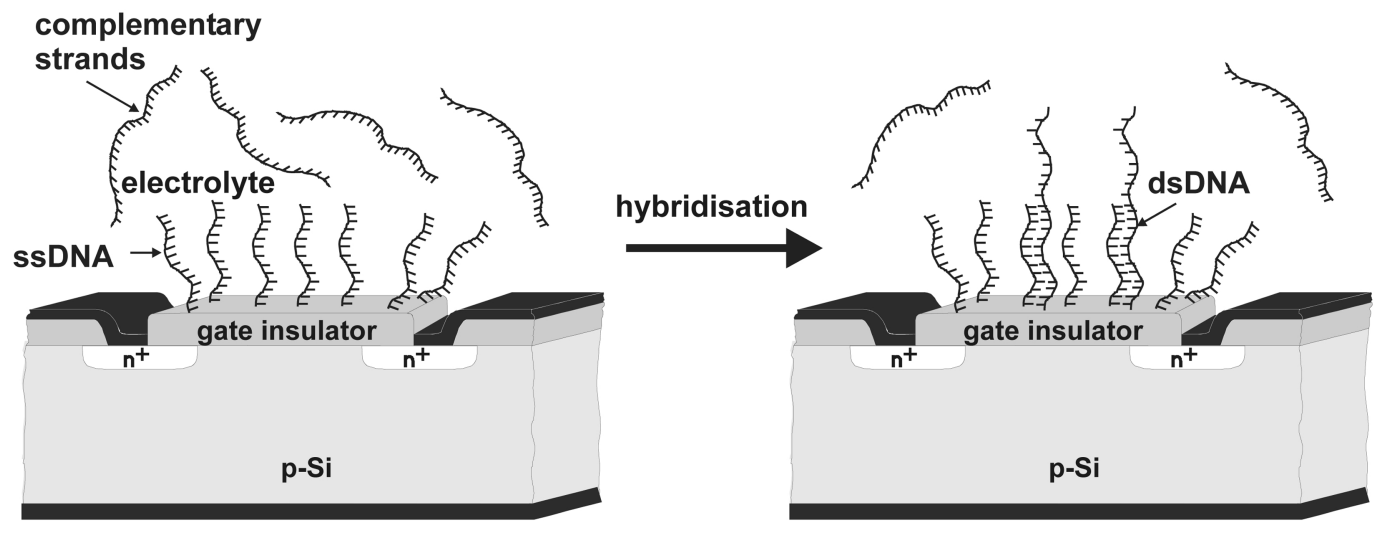

Fig. 8 Schematic structure of a DNA-FET (GenFET) and the principle of DNA-hybridisation detection. 
explain the experimental results. In this context, we would like to note the following: since DNA molecules are charged macromolecules, and since the direct hybridisation event is an affinity binding process, the practical realisation of a GenFET can yield the same problems as in the case of ImmunoFETs, i.e. the screening of macromolecule charges by small inorganic counter ions present in the solution (see section 3.2). In our opinion, however, in the case of the GenFET, there are some positive factors which can promote a successful measurement of a direct DNA hybridisation event.

These factors are as follows: (1) The unique structure of DNA molecules. DNA is, indeed, a poly-anion with negative charges along its phosphate backbone. It can be considered as a circular cylinder (with a diameter of about 1.5-2 nm) with electrostatic charges evenly distributed about the cylindrical surface; ${ }^{172}$ the length of a DNA probe depends on the number of nucleotides (to selectively recognise a unique human DNA sequence, DNA probes must be at least 16 bases long ${ }^{159}$ ). In the test solution, these negative charges are neutralised by positive inorganic counter ions. Since the length of a nucleotide (or base) is about $\sim 0.34 \mathrm{~nm},{ }^{48}$ the charge redistribution on the interface electrolyte/sensor resulting from the hybridisation process can be possible even in physiological solutions (with a double layer of about $\sim 1 \mathrm{~nm}$ ).

(2) Immobilisation of ssDNA by electrostatic attraction between the positively charged transducer surface and the negatively charged sugar-phosphate backbone with the bases oriented towards the solution. ${ }^{173}$ Also, in this case, the hybridisation process can effectively influence the distribution of the charge density in the double layer.

(3) The charged state of the surface on which ssDNA are immobilised. The thermodynamic theoretical analysis presented in ${ }^{174}$ shows that surface electrostatics of the substrate (i.e., negative or positive surface potential) drastically affect the DNA immobilisation and hybridisation process with the possibility of a DNA hybridisation control by regulation of the surface charge (potential). Thus, the construction of a GenFET with positive surface potential could be more attractive.

\subsection{Cell-based BioFET}

In this section, cell-based BioFETs, where the smallest selfsustaining biological entity, whole cells, are used as a recognition element, will be discussed. A 'cell-transistor' hybrid is obtained by direct coupling of a single cell or cell system to the gate insulator of a FET. Fig. 10(a) shows the schematic of a 'cell-transistor' hybrid and Fig 10(b) shows the videomicroscopic photo of genetically modified HEK 293 cells on an ISFET array (in the centre of the photo one cell completely covers the sensitive gate area of the ISFET).

For uniformity, in this article, we will use the term cell-based BioFET for both cell metabolism detection and extracellular potential measurement. For the electrogenic cell-transistor

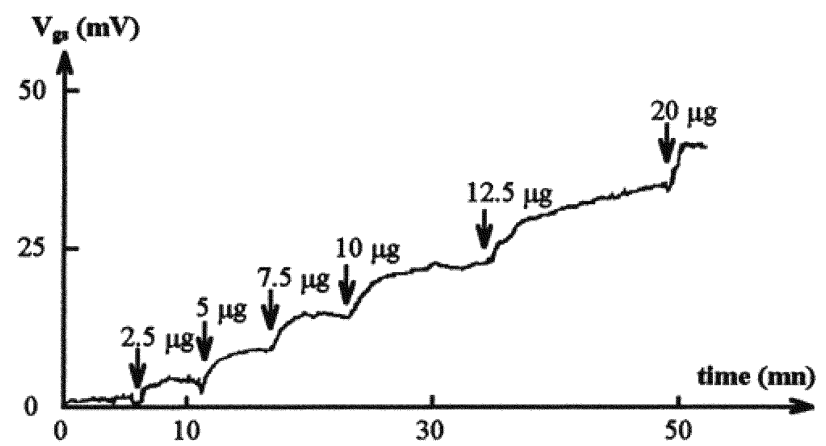

Fig. 9 Response of a GenFET to successive additions of the synthetic homo-oligomer poly $(\mathrm{dA}){ }^{83}$ hybrid the terms neuron-transistor ${ }^{81,175}$ or cell potential FET $(\text { CPFET })^{176,177}$ have also often been used to emphasize the pure extracellular potential measurements, although the gate insulator used (normally $\mathrm{SiO}_{2}$ or $\mathrm{Si}_{3} \mathrm{~N}_{4}$ ) is $\mathrm{pH}$ - or ion-sensitive, too.

Cells are highly organised living microstructures containing a high concentration of chemicals, including enzymes, nucleic acids, ions, many types of proteins and small organic molecules. They process multiple incoming information signals by means of a parallel activation of different signalling pathways and respond with an appropriate reaction pattern according to the type of input physical or chemical stimulus. In spite of the many difficulties and complications involved in using whole cells, including their limited lifespan, the most important reason for developing cell-based biosensors is that only by using living components capable of a direct response to incoming information can the effect of an external physical or chemical stimulus on a living system be investigated.52,178,179 This functional information with additional qualitative and/or quantitative analytical information can be very important with respect to clinical diagnostics, pharmacology and drug screening, cell biology, toxicology and environmental monitoring. By means of such biosensors, it could be possible to study the effects of pharmaceutical compounds, toxic substances, pollutants, etc., on a physiological system and in particular on cellular metabolism.

The state of a single cell or cell system can be monitored by means of various methods, which can be distinguished into two basic families. ${ }^{178}$ The first family of methods utilises the energy metabolism of cells and, in principle, can be extended to all cell types. It is sensitive to a wide range of cellular events, like

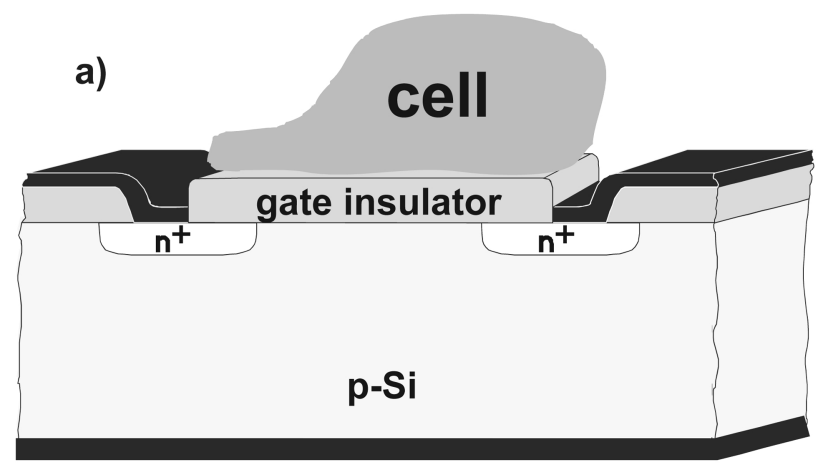

b)

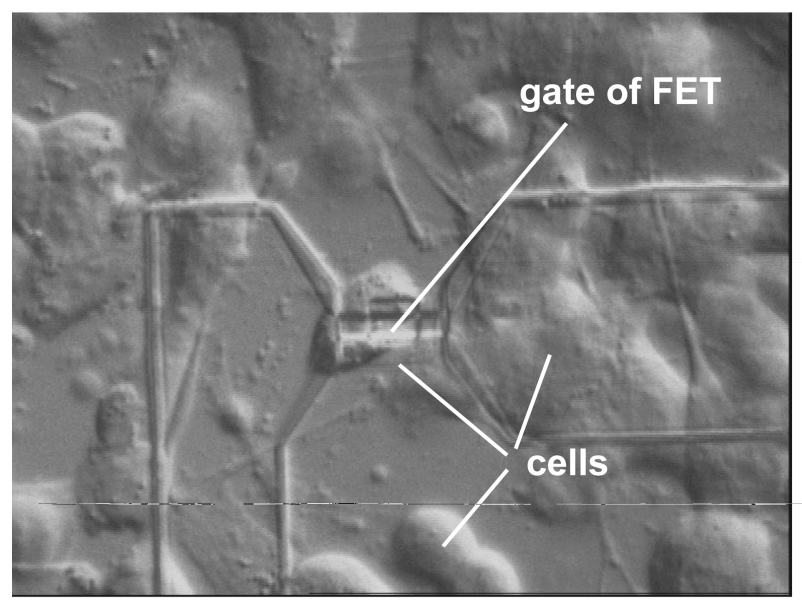

Fig. 10 'Cell-transistor' hybrid: (a) schematic set-up; (b) videomicroscopic photo of genetically modified HEK 293 cells on an ISFET array (unpublished photo, with kind permission of H. Ecken). In the centre of the photo one cell completely covers the sensitive gate area of the ISFET. 
growth, toxicity, etc. For example, mammalian cells constantly consume energy for synthesis of biological molecules, maintaining gradients of ionic concentration across the cell membrane, mechanical motion and for a variety of purposes. Fig. 11 shows the typical metabolic pathways, which lead to extracellular acidification. ${ }^{180}$ Signal parameters such as changes in the extracellular $\mathrm{pH}$, the concentration of ions, oxygen consumption, $\mathrm{CO}_{2}$ production, the redox potential and other metabolic products (e.g., glucose and lactate) can be measured by various well-established ISFET-based single chemical sensors and biosensors, or multi-parameter sensor systems. Bergveld first employed the $\mathrm{SiO}_{2}$-gate ISFET for the extracellular ion-concentration measurement. ${ }^{181}$ More recently, cell-based BioFETs with $\mathrm{Si}_{3} \mathrm{~N}_{4}$ or $\mathrm{Al}_{2} \mathrm{O}_{3}$ as pH-sensitive gate insulators have been realised for extracellular acidification as well as for respiration (oxygen consumption) measurements. ${ }^{176,177,182-188}$

The principle of the extracellular acidification measurement with a cell-based BioFET can be briefly described as follows: usually, the measurements of the acidification rate are performed in a flow-through chamber with an array of cell-based BioFETs, operated in the flow-stop mode. Under steady-state conditions (pump on), one cell (approximately 105-106 cells can be cultivated on a sensor chip) produces about $\sim 10^{8}$ protons per second. After an external receptor stimulation this quantity of protons will be raised to between 10 and $100 \%$ depending on the cell type, the receptor and the coupling pathway. ${ }^{180}$ When the pump is stopped, the produced protons accumulate and acidify the extracellular medium. Thus, changes in the extracellular acidification rate caused by different external stimuli (e.g., by addition of drugs or toxic agents to the medium) can be detected by the underlying $\mathrm{pH}$ sensitive ISFET. In order to obtain a high sensitivity, a very small chamber volume (usually in $\mu 1$ range) is required. In principle, the ISFET can also be capable of detecting the rate of acidification from a single cell. The main remaining technical problem, however, is the need for confining the produced protons to a given small volume.

Because cells respond to external stimuli with a parallel activation of different signalling pathways (see Fig. 11), the measurement of only one integral parameter such as the acidification rate, is often insufficient for a clear interpretation of different effects on living cells. Therefore, the on-line, parallel and non-invasive measurement of different parameters is very helpful. The so-called PhysicoControl Microsystem (PCM) and Cell Monitoring System (CMS), which combine

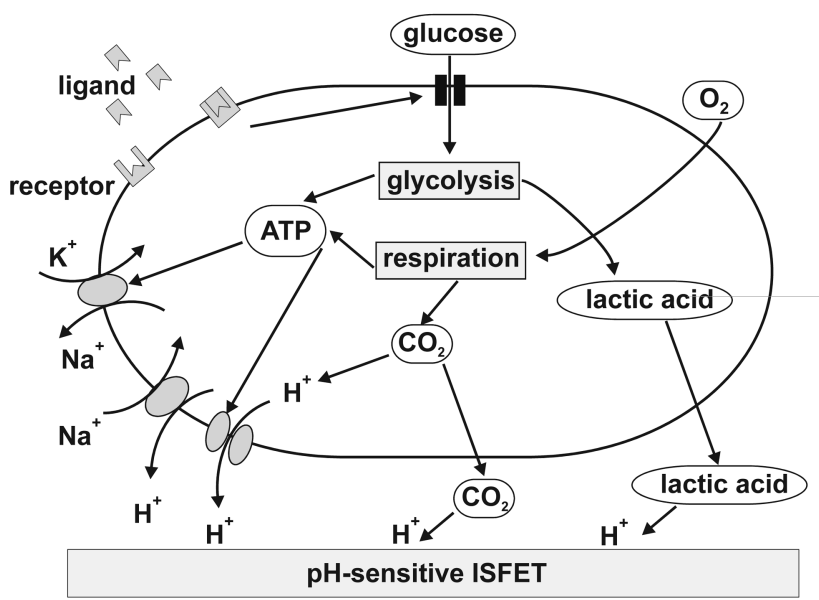

Fig. 11 The cell biology of extracellular acidification: upon receptor stimulation, signal transduction pathways are induced. The corresponding ATP consumption is compensated by the increased uptake and metabolism of glucose, which results in an increase in the excretion of acid waste products. The extracellular acidification can be measured by field-effect sensors (e.g., LAPS or ISFET). ${ }^{180}$ different microsensors, including arrays of $\mathrm{pH}$ ISFETs and CPFETs with different gate areas (from a few $\mu \mathrm{m}^{2}$ for single cell measurement up to $6000 \mu \mathrm{m}^{2}$ for cell population) and with different gate materials $\left(\mathrm{SiO}_{2}, \mathrm{SiO}_{2}-\mathrm{Si}_{3} \mathrm{~N}_{4}\right.$ and $\mathrm{SiO}_{2}-\mathrm{Al}_{2} \mathrm{O}_{3}$ double layer) have been developed. ${ }^{176,177,185,186}$ Moreover, recently the feasibility of simultaneous measurement of both the acidification and the respiration (oxygen consumption) at the same site in a cell culture by using a single cell-based BioFET configuration with a surrounding noble metal electrode for oxygen reduction and $\mathrm{OH}^{-}$ion generation, has been demonstrated. ${ }^{187}$ A similar, completely automated cell monitoring microsystem, combining an array of 12 ISFETs, temperature sensor and conductivity sensor, is described in ref. 188

In comparison to the commercially available Cytosensor Microphysiometer system (Molecular Devices Corp.) for cellular acidification measurement, ${ }^{180}$ which is based on a LAPS (light-addressable potentiometric sensor), the advantages of a cell-based BioFET system are the further miniaturisation potential by integrating the ISFETs with other semiconductor microsensors together with the sensor electronics on one single sensor chip. Such a set-up guarantees statistically reliable results by using an array of cell-based BioFETs and also the possibility to combine this system together with a light microscope for optical imaging. ${ }^{177}$ On the other hand, the LAPS are simpler in fabrication. ${ }^{182}$ The possible scientific applications of such a system concern all aspects of metabolismaffecting pathways, while commercial aspects mainly concern pharmacological and toxicological questions. 183,185,186,189

The second family of cellular measurement methods mostly utilises specific features of certain types of electrogenic cells such as neuronal cells, muscle cells or cell networks and include extracellular and intracellular potential measurements. The first attempt to apply an ISFET in neurophysiological measurements was made in $1970 .{ }^{18}$ An ISFET was also chosen to record the extracellular voltage from muscle tissues, ${ }^{190}$ and FET arrays with 'floating' gold-gate have been used to record potential changes of neuronal slices. ${ }^{80}$ More recently, the first recording from single invertebrate neurons ${ }^{81}$ and vertebrate neurons ${ }^{191}$ as well as cardiac myocyte monolayers ${ }^{192}$ cultered on the gate insulator of a FET was reported (see also the review, 179). Electrogenic cells generate spontaneous or triggered action potentials (transient changes of their membrane potentials) that can be measured by a 'neuron-FET' hybrid. With the help of an additional insulated spot of silicon, a capacitive extracellular stimulation of an individual neuron was demonstrated to be possible ${ }^{193}$ and even a bi-directional interface between neuron and transistor has been developed. ${ }^{194}$ This interface facilitates both a capacitive stimulation and a capacitive recording of the neural activity of cells cultured onto the gate of an ISFET.

Different approaches have been proposed that describe the signal transfer from electrogenic cells to a FET and explain the recorded signal behaviour (shape and amplitude). A commonly used approach is the point contact model. ${ }^{179,192}$ For the interpretation of some effects (for instance, a high ionic conductance in the cleft between cell and transistor, the time delay of the extracellular signal, etc.) which are observed in the experiments with neuronal cells, different extended models have also been reported. ${ }^{192,195,196}$ However, all these models ignore the $\mathrm{pH}$ - and/or certain ion-sensitive properties of the gate insulator (usually $\mathrm{SiO}_{2}$ or $\mathrm{Si}_{3} \mathrm{~N}_{4}$ ) that can also be a source of interfacial potential changes in the region of the neuron adhesion, and thus, can play a major role in the coupling behaviour of cells to the FET and consequently, in the recording signal. This fact was already mentioned by Bergveld ${ }^{181}$ and Grattarola. ${ }^{197}$ Recently, it was also reported by Fromherz ${ }^{198}$ that a change of local potassium concentration within the narrow gap between cell and transistor $(\sim 50 \mathrm{~nm})$ during channel activation may also modulate the electrical double layer in front of the gate oxide and affect the transistor. It seems that the ideas and experience in the field of the development of a 
reference FET (see e.g., ref. 60), for example, by using thin polymer films with a very small amount of surface active sites $\left(\sim 10^{12} \mathrm{~cm}^{-2}\right)$, which possess very low $\mathrm{pH}-$ and/or ionsensitivity properties, can also be very useful in understanding these phenomena in more detail.

The coupling strength between a neuron and a microelectronic chip, i.e. the adhesion 'quality' of neurons to the transducer surface is the most critical parameter that may seriously change the features of the recorded extracellular signals. Therefore, the determination of the width of the cleft and the measurement of the specific resistance in the region of adhesion were attempted. ${ }^{199}$ It was found that the specific resistance in the cleft is a factor 4 larger than the specific resistance of the bulk electrolyte. ${ }^{199}$ The issues of cell attachment and growth on a modified microelectronic device surface, ${ }^{200}$ on silicon nanostructures, ${ }^{201}$ on microperforated silicon membranes ${ }^{202}$ as well as on 3-dimensionally microstructured silicon wafers (grooves and square wells with different dimensions $)^{203}$ have also been studied.

In addition to neuronal cells, cardiac muscle cells represent an interesting electrically active system that processes biological information. The spontaneous rhythmic electrical and mechanical activity of cultered myocardiac cells is widely used in the study of cardiac physiology. Their beating frequency can be changed with cardiac stimulants and relaxants. Recently, the electrical recording from rat cardiac muscle cells using a bioelectronic device, which consists of an array of 16 FETs (for the technological detail see ref. 204), have been reported. A long-term and multisite recording system for monitoring electrogenic cells in culture have been discussed, too. ${ }^{205}$ As an example, Fig. 12 shows the electrical recording signal from cardiac myocytes. For comparison, the measurements were simultaneously performed both extracellularly using a FET (lower curve) and intracellularly using a microelectrode (upper curve). Furtheremore, this system was adapted for recording the effects of different drugs (cardiac stimulants and relaxants) on cardiac myocytes. ${ }^{206,207}$ The change in the beat frequency of heart cells in the presence of norepinephrine and isoproterenol shows a distinct concentration dependence between 0.01 and 10 $\mu \mathrm{M}$. These results demonstrate the potential of a cell-transistor hybrid system for drug testing applications.

Finally, neuronal cell networks coupled with FET networks are also perspective candidates for both fundamental study of signal transduction and propogation between interconnected cells, and for pharmacological and toxicological applications. The aim is mainly to create a 2-dimensional communication between the cells and microelectronic transducers. Recent attempts in this field show the possibility of creation of small neural networks using micro-contact printing 208,209 or lithographic technology. ${ }^{210}$ However, progress in this field will depend on a successful solution of some problems concerning the technological realisation of large networks, the signal-tonoise ratio, the large amount of data which needs to be
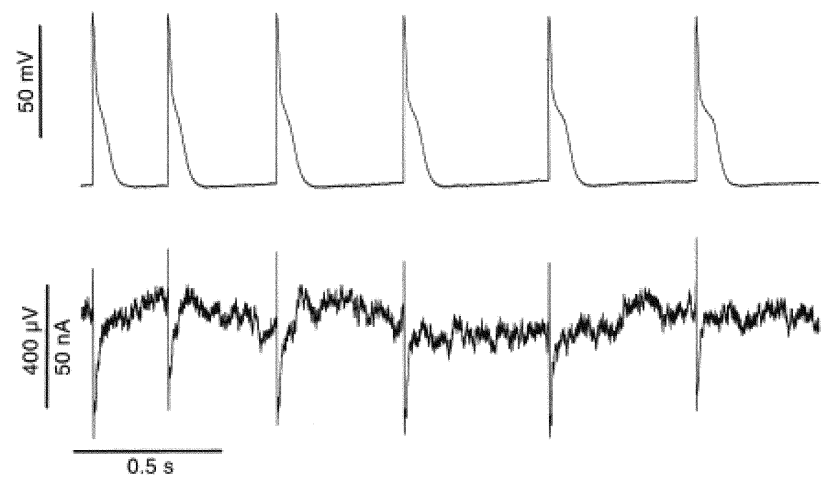

Fig. 12 Intracellular (upper curve, with microelectrode) and extracellular (lower curve, with FET) recording of cardiomyocytes. ${ }^{205}$ processed as well as the lack of a clear understanding of the complex neuronal networks response.

\section{5. 'Beetle/chip' FET}

Taking whole animals or at least complete sensory organs (e.g., insect antenna) as a biological recognition element comprises a new trend in bioelectronic sensor development, although this idea was introduced by Rechnitz in $1986 .{ }^{211}$ For example, insects are known for their specially developed sense of smell. Among the approximately one million insect species, only about 250 have been tested for their olfactory abilities so far. About 250 pheromones and about 400 host plant odours are known that can be detected with extremely high sensitivity and selectivity using these unique features of insects.

A design to couple an insect antenna directly to a FET, thereby creating a completely new type of biosensor, a so-called 'beetle/chip' sensor, was first realised ${ }^{82}$ and then investigated in detail and optimised. ${ }^{212-220}$ In this approach, the voltage generated in the antenna upon detecting a certain odour is used to modify the drain current of the transitor. The responsible organ for smell, i.e. the insect antenna, usually consists of several segments, equipped with small hairs, the so-called sensilla, which contain the olfactory receptor neurons. The odour recognition process is initiated at the nerve cell membranes. As a result of odour stimulation, an odour concentration-dependent voltage pulse is generated over the whole antenna yielding a dipole that leads to respective peaks in the drain current of the FET. For details of the odour-detection mechanism of the 'beetle/chip' sensor see refs 215, 217 and 221.

In order to measure the signals generated in the insect antenna, a bioelectronic interface has to be established between the insect antenna and the FET. Generally, there are two possible configurations of coupling the antenna to the FET. ${ }^{213}$ The first configuration is a whole beetle BioFET, where the whole beetle is fixed in a cell and the tip of the insect antenna is dipped into an electrolyte solution that is in direct contact with the gate insulator of the FET as schematically shown in Fig. 13(a). A reference electrode, e.g. platinum wire, has then to be placed into an appropriate site of the beetle, e.g. between the neck and the head. In the second configuration, the isolated antenna BioFET, the antenna is dissected from the beetle and contacted on both sides with the electrolyte solution (Fig. 13(b)). If now an air current, loaded with a marker compound is flushed over the antenna (set-up (a) or (b)), the induced depolarisation response will modify the conductance of the FET channel between source and drain, yielding a change in the drain current as sensor signal.

As an example, Fig. 14(a) presents a typical dose-response curve of the 'beetle/chip' sensor with the antenna of a Colorado potato beetle. The odour pulses are different concentrations of the specific green-leaf odour cis-3-hexen-1-ol in air from $1 \mathrm{ppt}$ to $100 \mathrm{ppm}$. As can be seen, the peak size of the sensor response clearly depends on the respective odour quantity. The more intense the odour stimulus for the antenna, the higher the recorded signal. The sensor signal is given by drain-current changes in the $\mu \mathrm{A}$ range. In this experiment, the measurements were performed using a specific sensor head with antenna holder and a BioFET-based sensor system, which provides a stream of air with constant temperature, humidity and velocity as well as the injection of the respective odour pulses. ${ }^{214,220}$ This BioFET-based 'beetle/chip' sensor enables the detection of odour concentrations down to the ppt concentration range (Fig. 14(b)). ${ }^{219}$ The signal-to-noise ratio of the 'beetle/chip' FET was improved by choosing an appropriate gate layout ${ }^{214}$ and the biological receptor part of the sensor, i.e. the insect antenna, was characterised by means of impedance spectroscopy in order to 
obtain information about the electrical behaviour of the antenna. ${ }^{217}$

One interesting application of the developed 'beetle/chip' sensor is in the detection of plant damage in potato fields in order to determine the right timing for pesticide application. For example, thousands of potato fields annually fall prey to the

a)
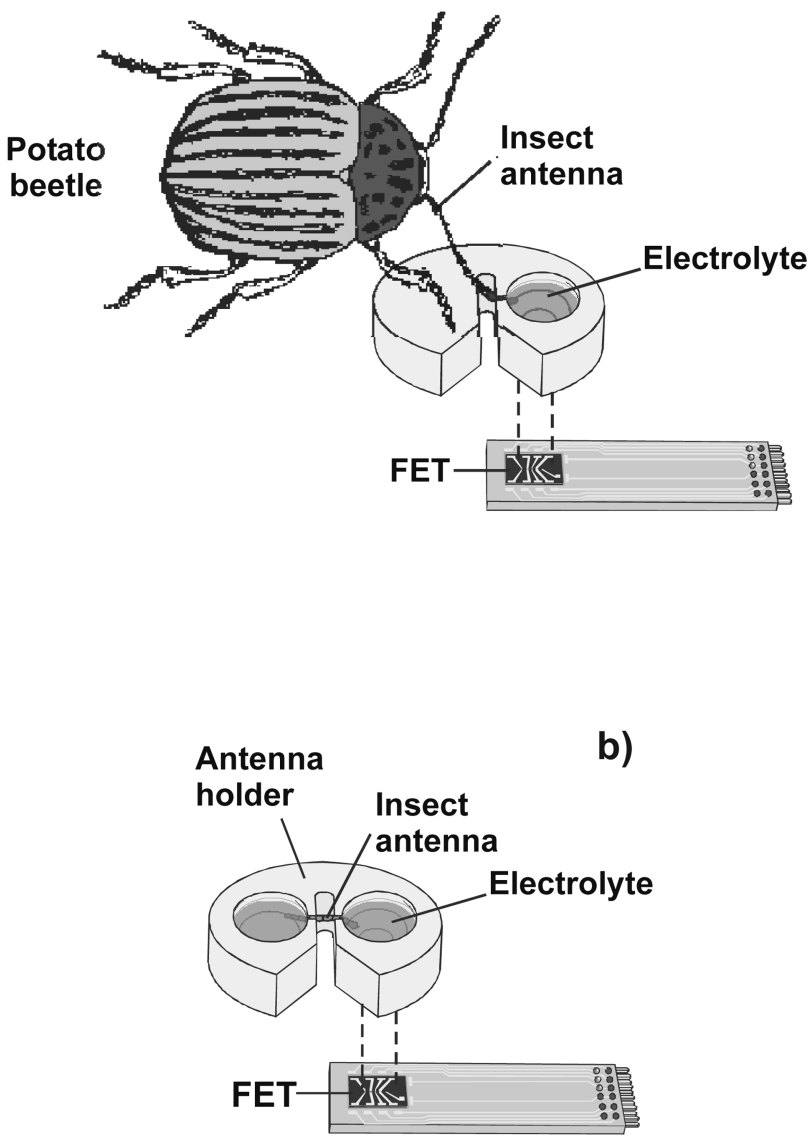

Fig. 13 Two general configurations of coupling an insect antenna as biorecognition component to a FET: (a) 'whole-beetle' BioFET and (b) 'isolated-antenna' BioFET. The antenna is highly sensitive towards different odour concentrations.

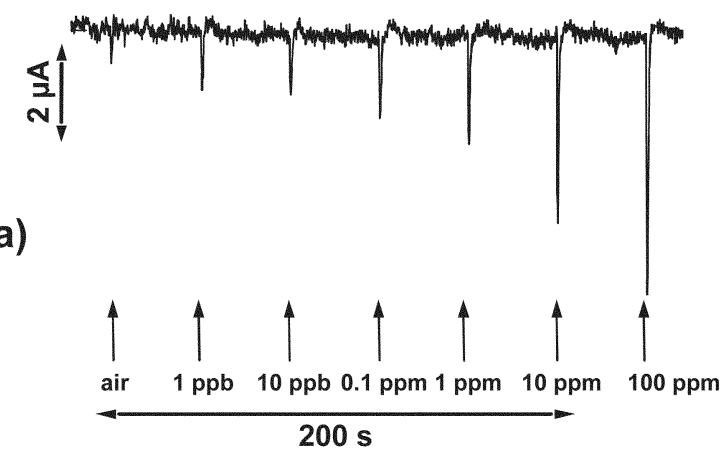

b)

\begin{tabular}{c|c|c} 
odour beetle & potato beetle & jewel beetle \\
\hline cis-3-hexen-1-ol & ++ & $+++(1 \mathrm{ppt} . . .100 \mathrm{ppm})$ \\
\hline guaiacol & + & $++(50 \mathrm{ppt} . .500 \mathrm{ppb})$ \\
\hline 1-octen & $\begin{array}{l}+ \\
\text { (15 ppb... 1.5 ppm) }\end{array}$ &
\end{tabular}

Fig. 14 Typical dose-response curve of the 'beetle/chip' sensor with the antenna of a Colorado potato beetle towards odour pulses of different concentrations of the green-leaf odour, cis-3-hexen-1-ol, in air (a) and list of detectable odour substances with their respective concentration ranges (b). The increasing number of ' + ' indicates the higher sensitivity. potato beetle. As a consequence, many farmers spray large quantities of pesticides that mainly save the harvest, but simultaneously contaminate the soil and groundwater and kill useful insects. By means of the developed bioelectronic device, a field's infestation with beetles could be identified at an early stage. Another application might be in an early fire alarm system: smouldering fires such a burning coal, paper and wood, can be detected by means of monitoring fire-specific odours (e.g., guaicol and 1-octen) using the same biosensor only with the antenna of a steelblue jewel beetle instead. ${ }^{215,219}$

At present, the 'beetle/chip' biosensor is still at the development stage but it shows great promise for the future. The possible field of applications can be extended by employing various insect species with different sensitivity profiles. Therefore, it is of value to construct a library of beetle species with their odour detection spectra.

\section{Conclusion and perspectives}

Thirty years have elapsed since the invention of the ISFET by Bergveld. Since that time, various types of BioFETs have been developed using different biological recognition elements starting with enzymes and immunological species through DNA molecules to living cells and even living organisms. The study of the current state of BioFETs reveals that some BioFETs, like EnFETs are at a well-developed stage, whereas other BioFETs such as GenFETs and 'beetle/chip' FETs are in the initial stages of development. There are still a number of fundamental and technological problems that must be overcome, before the first reliable BioFET-based bioanalytical microsystem will appear on the market. Therefore, intensive interdisciplinary research and cooperation of specialists from different disciplines is still required, not only in the field of biotechnology and bioengineering but also in related disciplines, like informatics, solid-state physics, microtechnology, genetics as well as specific techniques such as sensor integration and packaging, interfacing circuits, etc.

Hence, future prospects for BioFET developments can be expected in the following directions: (i) BioFETs utilising intact biological receptors (ion channel receptors, binding proteins, etc.) that bind specific drugs and reagents in such a way that they produce a conformational change in the protein structure. This conformational change, in turns, triggers a cellular response, (e.g., the opening of an ion channel of the membrane (so-called ion-channel switch biosensor); (ii) ISFET-based DNA chips can be considered as a new tool for the simultaneous analysis of thousands of nucleic acids with a broad area of potential applications in biomedical research and clinical diagnostics, genomics, drug screening, environmental monitoring and food industry. They combine both the possibility of direct DNA hybridisation detection without the use of labelled probes and the large integration ability of these active microelectronic devices (high density arrays of active areas up to $10^{5} \mathrm{~cm}^{-2}$ can be achieved); (iii) The creation of large neuronal networks on a CPFET array and thus, a better understanding of 'in-situ' complex neurobiological responses of neuronal networks, which can open up new avenues for, (e.g., drug screening; and (iv) The integration of BioFETs in bioanalytical microsystems, including other chemical and physical sensors, actuators as well as fluidic components. The recently developed concept of a combination of (bio-)chemical and physical sensors using an identical transducer principle $^{111,222}$ can serve to be an innovative way to create costeffective modules for bioanalytical microsystems.

The listed examples appear to be incomplete, since at least 10 new ideas and concepts in the field of BioFETs are submitted in different scientific journals during the writing of this review. But this fact emphasizes the exciting nature of the subject. 
Consequently, in the near future, a multitude of interesting BioFETs.

\section{Acknowledgements}

The authors thank H. Ecken, A. Offenhäusser, P. Schroth and S. Schütz for valuable discussions.

\section{References}

1 L. C. Clark and C. Lyons, Ann. N.Y. Acad. Sci., 1962, 102, 29-45.

2 A. Manz, N. Gruber and H. M. Widmar, Sens. Actuators, B, 1990, 1, 244-248.

3 Micro Total Analysis Systems, ed. A. van den Berg, W. Olthuis and P. Bergveld, Kluwer, Dordrecht, 2000.

4 S. Shoji, in Sensors Update, ed. H. Baltes, W. Göpel and J. Hesse, Wiley, Weinheim, 2000, pp. 3-17.

5 A. van den Berg and T. S. J. Lammerink, Top. Curr. Chem., 1997, 194, 21-49.

6 R. Rapp, W. Hoffmann, W. Süß, H. J. Ache and H. Gölz, Electrochim. Acta, 1997, 42, 3391-3398.

7 P. Arquint, M. Koudelka-Hep, B. H. van der Schoot, P. van der Wal and N. F. de Rooij, Clin. Chem., 1994, 40, 1805-1809.

8 S. C. Jakeway, A. J. de Mello and E. L. Russel, Fresenius' J. Anal. Chem., 2000, 366, 525-539.

9 E. Dempsey, D. Diamond, M. R. Smyth, G. Urban, G. Jobst, I. Moser, E. M. J. Verpoorte, A. Manz, H. M. Widmar, K. Rabenstein and R. Freaney, Anal. Chim. Acta, 1997, 346, 341-349.

10 K. K. Jain, Trends Biotechnol., 2000, 18, 278-280.

11 C. Krantz-Rülcker, M. Stenberg, F. Winquist and I. Lundström, Anal. Chim. Acta, 2001, 426, 217-226.

12 K. Toko, Biosens. Bioelectron., 1998, 13, 701-709.

13 A. V. Legin, A. M. Rudnitskaya, Yu. Vlasov, C. Di Natale, E. Mazzone and A. D'Amico, Sens. Actuators, B, 2000, 65, 232-234.

14 F. Winquist, I. Lundström and P. Wide, Sens. Actuators, B, 1999, 58, 512-517

15 D. J. Strike, M. G. H. Meijerink and M. Koudelka-Hep, Fresenius ' J. Anal. Chem., 1999, 364, 499-505.

16 M. A. Craven, J. W. Gardner and P. N. Bartlett, Trends Anal. Chem., 1996, 15, 486-493.

17 W. Göpel, Sens. Actuators, B, 1998, 52, 125-142.

18 P. Bergveld, IEEE Trans. Biomed. Eng., 1970, 17, 70-71.

19 D. R. Thevenot, K. Toth, R. A. Durst and G. S. Wilson, Biosens Bioelectron., 2001, 16, 121-131.

20 K. Cammann, B. Ross, A. Katerkamp, J. Reinbold, B. Gründig and R. Renneberg, in Handbook of Analytical Techniques, ed. H. Günzler and A. Williams, Wiley, Weinheim, 2001, vol. 2, pp. 951-1059.

21 Handbook of Chemical and Biological Sensors, ed. R. F. Taylor and J. S. Schultz, IOP Publishing Ltd, Bristol, 1996.

22 Frontiers in Biosensorics: Fundamental Aspects, ed. F. W. Scheller, F. Schubert and J. Fedrowitz, Birkhäuser Verlag, Berlin, 1997.

23 Frontiers in Biosensorics: Practical Applications, ed. F.W. Scheller F. Schubert and J. Fedrowitz, Birkhäuser Verlag, Berlin, 1997.

24 E. A. H. Hall, Biosensors, Open University Press, Milton Keynes, 1990.

25 Biosensors: Fundamentals and Applications, ed. A. P. F. Turner, I. Karube and G. S. Wilson, Oxford University Press, Oxford, 1987.

26 Biosensors: A Practical Approach, ed. A. E. G. Cass, IRL Press, Oxford, 1990

27 U. E. Spichiger-Keller, Chemical Sensors and Biosensors for Medical and Biological Applications, Wiley, Weinheim, 1998.

28 Sensors: A Comprehensive Survey: Chemical and Biochemical Sensors, ed. W. Göpel, J. Hesse and J. N. Zemel, Wiley, Weinheim, vol. 2, 1991.

29 Sensors: A Comprehensive Survey: Chemical and Biochemical Sensors, ed. W. Göpel, J. Hesse and J. N. Zemel, Wiley, Weinheim, vol. 3, 1992.

30 Handbook of Biosensors and Electronic Noses: Medicine, Food and the Environment, ed. E. Kress-Rogers, CRS Press, 1997.

31 Enzyme and Microbial Biosensors, ed. A. Mulchandani and K.R. Rogers, Humana Press, Totowa, New Jersey, 1998.

32 M. Valcarcel and M. D. Luque de Castro, Flow-through (Bio)chemical Sensors, Elsevier, Amsterdam, 1994.

33 Biosensors for Environmental Monitoring, ed. U. Bilitewski, Harward Academic Publ., Amsterdam, 2000
34 Commercial Biosensors: Applications to Clinical, Bioprocess, and Environmental Samples, ed. G. Ramsay, Wiley, New York, 1998.

35 Principles of Chemical and Biological Sensors, ed. D. Diamond, Wiley, New York, 1998.

36 Biosensors: Microelectrochemical Devices, ed. M. Lambrechts and W. Sansen, IOP Publishing Ltd, Bristol, 1992.

37 M. Grattarola and G. Massobrio, Bioelectronics Handbook: MOS FETs, Biosensors, and Neurons, McGraw-Hill, New York, 1998.

38 F. W. Scheller, U. Wollenberger, A. Warsinke and F. Lisdat, Curr. Opin. Biotechnol., 2001, 12, 35-40.

39 U. Wollenberger, R. Hintsche and F. Scheller, Microsys. Technol., 1995, 1, 75-83.

40 P. Bergveld, Sens. Actuators, A, 1996, 56, 65-73.

41 I. E. Tothill, Comput. Electron. Agriculture, 2001, 30, 205-218.

42 V. Tvarozek, T. Hianok, I. Novotny, V. Rehacek, W. Ziegler, R. Ivanic and M. Andel, Vacuum, 1998, 50, 251-262.

43 J. Hu, Sens. Mater., 1996, 8, 477-484.

44 A. N. Reshetilov, Appl. Biochem. Microbiol., 1996, 32, 72-85.

45 M. P. Byfield and R. A. Abuknesha, Biosens. Bioelectron., 1994, 9, 373-400

46 R. S. Sethi, Biosens. Bioelectron., 1994, 9, 243-264.

47 M. P. Marco and D. Barcelo, Meas. Sci. Technol., 1996, 7, 1547-1562.

48 T. Vo-Dinh and B. Cullum, Fresenius' J. Anal. Chem., 2000, 366, 540-551.

49 M. Cardosi and B. Haggett, in Sensor Systems for Environmental Monitoring, ed. M. Campbell, Chapman and Hall, London, 1997, pp. 210-267.

50 K. R. Rogers, Biosens. Bioelectron., 1995, 10, 533-541.

51 B. M. Paddle, Biosens. Bioelectron., 1996, 11, 1079-1113.

52 C. Ziegler, Fresenius' J. Anal. Chem., 2000, 366, 552-559.

53 G. Urban, in Sensors Update, ed. H. Baltes, W. Göpel and J. Hesse, vol. 8, Wiley, Weinheim, 2001, pp. 189-214.

54 A. Manz and R. C. Anderson, Microsystem Technology in Chemistry and Life Science, Springer, Berlin, 1998.

55 H. H. Weetall, Biosens. Bioelectron., 1966, 11, I-IV

56 H. H. Weetall, Biosens. Bioelectron., 1999, 14, 237-242.

57 J. Janata and R. J. Huber, Solid State Chemical Sensors, Academic Press, Orlando, 1985.

58 A. Sibbald, J. Mol. Electron., 1986, 2, 51-83.

59 G. F. Blackburn, in Biosensors: Fundamentals and Applications, ed. A. P. F. Turner, I. Karube and G. S. Wilson, Oxford University Press, Oxford, 1987, pp. 481-530.

60 P. Bergveld and A. Sibbald, Analytical and Biomedical Applications of Ion-Selective Field-Effect Transistors, Elsevier, Amsterdam, 1988.

61 I. Lundström, A. van den Berg, B. H. van der Schoot, H. H. van den Vlekkert, M. Armgarth and C. I. Nylander, in Sensors: A Comprehensive Survey, ed. W. Göpel, J. Hesse and J. N. Zemel, 1991, vol. 2, pp. 467-528.

62 A. Lui, B. Margesin, M. Zen, G. Soncini and G. Verzellesi, Informacije MIDEM, 1996, 26, 238-250.

63 C. Cane, I. Gracia and A. Merlos, Microelectron. J., 1997, 28 , 389-405.

64 A. K. Covington, Pure Appl. Chem., 1994, 66, 565-569.

65 J. Janata, M. Josowicz, P. Vanysek and D. M. DeVaney, Anal. Chem., 1998, 70, 179R-208R

66 M. Chudy, W. Wroblewski, A. Dybko and Z. Brzozka, Sens Actuators, B, 2001, 78, 320-325.

67 C. Jimenez, I. Marques and J. Bartroli, Anal. Chem., 1996, 68, 3801-3807.

68 W. Gumbrecht, W. Schelter, B. Montag, M. Rasinski and U. Pfeiffer, Sens. Actuators, B, 1990, 1, 477-480.

69 K. Tsukada, Y. Miyahara, Y. Shibata and H. Miyagi, Sens. Actuators, B, 1990, 2, 291-295.

70 W. Moritz, F. Lisdat, B. H. van der Schoot, N. F. de Rooij, H. H. van der Vlekkert, H. C. G. Ligtenberg and I. Grohmann, Sens. Actuators, B, 1993, 15-16, 223-227.

71 Z. Elbhiri, Y. Chevalier, J. M. Chovelon and N. Jaffrezic-Renault, Talanta, 2000, 52, 495-507.

72 N. Abramova, Yu. Borisov, A. Bratov, P. Gavrilenko, C. Dominguez, V. Spiridonov and E. Suglobova, Talanta, 2000, 52, 533-538.

73 G. Taillades, O. Valls, A. Bratov, C. Dominguez, A. Pradel and M. Ribes, Sens. Actuators, B, 1999, 59, 123-127.

74 R. E. G. van Hal, J. C. T. Eijkel and P. Bergveld, Sens. Actuators, B, 1995, 24-25, 201-105.

75 R. E. G. van Hal, J. C. T. Eijkel and P. Bergveld, Adv. Colloid Interface Sci., 1996, 69, 31-62.

76 A. Poghossian, A. Baade, H. Emons and M. J. Schöning, Sens Actuators, B, 2001, 76, 634-638.

77 J. Janata and S. Moss, Biomed. Eng., 1976, 11, 241-245. 
78 S. Caras and J. Janata, Anal. Chem., 1980, 52, 1935-1937.

79 J. F. Schenck, > in Theory, Design and Biomedical Applications of Solid State Chemical Sensors, ed. P. W. Cheung, CRC Press, Boca Raton, 1978, pp. 165-173.

80 D. T. Jobling, J. G. Smith and H. V. Wheal, Med. Biol. Eng. Comput., 1981, 19, 553-560.

81 P. Fromherz, A. Offenhäusser, T. Vetter and J. Weis, Science, 1991, 252, 1290-1293.

82 S. Schütz, B. Weissbecker, H. E. Hummel, M. J. Schöning, A. Riemer, P. Kordos and H. Lüth, Naturwissenschaften, 1997, 84, 86-88.

83 E. Souteyrand, J. P. Cloarec, J. R. Martin, C. Wilson, I. Lawrence, S. Mikkelsen and M. F. Lawrence, J. Phys. Chem. B, 1997, 101, 2980-2985.

84 B. H. van der Schoot and P. Bergveld, Biosensors, 1987/88, 3, $161-186$.

85 R. Ulber and T. Scheper, in Enzyme and Microbial Biosensors, ed. A. Mulchandani and K. R. Rogers, Humana Press, Totowa, New Jersey, 1998, pp. 35-50.

86 K. Wan, J. M. Chovelon, N. Jaffrezic-Renault and A. P. Soldatkin, Sens. Actuators, B, 1999, 58, 399-408.

87 C. Puig-Lleixa, C. Jimenez, J. Alonso and J. Bartroli, Anal. Chim. Acta, 1999, 389, 179-188.

88 N. F. Staradub, W. Torbicz, D. Pijanowska, V. M. Staradub, M. I. Kanjuk and M. Dawgul, Sens. Actuators, B, 1999, 58, 420-426.

89 N. Jaffrezic-Renault, A. Senillou, C. Martelet, K. Wan and J. M. Chovelon, Sens. Actuators, B, 1999, 59, 154-164.

90 H. I. Seo, C. S. Kim, B. K. Sohn, T. Yeow, M. T. Son and M. Haskard, Sens. Actuators, B, 1997, 40, 1-5.

91 C. H. Lee, H. I. Seo, Y. C. Lee, B. W. Cho, H. Jeong and B. K. Sohn, Sens. Actuators, B, 2000, 64, 37-41.

92 B. K. Sohn, B. W. Cho, C. S. Kim and D. H. Kwon, Sens. Actuators, B, 1997, 41, 7-11.

93 V. Volotovsky, A. P. Soldatkin, A. A. Shul'ga, V. K. Rossokhaty, V. I. Strikha and A. V. El'skaya, Anal. Chim. Acta, 1996, 322, 77-81.

94 A. Poghossian, Sens. Actuators, B, 1997, 44, 361-364.

95 A. B. Kharitonov, M. Zayats, A. Lichtenstein, E. Katz and I. Willner, Sens. Actuators, B, 2000, 70, 222-231.

96 K. Y. Park, M. Lee and B. K. Sohn, Electron. Lett., 2001, 37, 495-497.

97 K. Y. Park, S. B. Choi, M. Lee, B. K. Sohn and S. Y. Choi, Sens. Actuators, B, 2002, 83, 90-97.

98 V. Volotovsky and N. Kim, Sens. Actuators, B, 1998, 49, 253-257.

99 L. T. Yin, J. C. Chou, W. Y. Chung, T. P. Sun, K. P. Hsiung and S. K. Hsiung, Sens. Actuators, B, 2001, 76, 187-192.

100 S. V. Dzyadevich, Y. I. Korpan, V. M. Arkhipova, M. Yu. Alesina, C. Martelet, A. V. El'skaya and A. P. Soldatkin, Biosens. Bioelectron., 1999, 14, 283-287.

101 T. Kullick, U. Bock, J. Schubert, T. Scheper and K. Schügerl, Anal. Chim. Acta, 1995, 300, 25-31.

102 D. G. Pijanowska and W. Torbicz, Sens. Actuators, B, 1997, 44, 370-376.

103 D. V. Gorchkov, A. P. Soldatkin, S. Poyard, N. Jaffrezic-Renault and C. Martelet, Mater. Sci. Eng., 1997, C 5, 23-28.

104 D. V. Gorchkov, A. P. Soldatkin, S. Poyard, N. Jaffrezic-Renault and C. Martelet, Mater. Sci. Eng., 1997, C 5, 29-34.

105 C. Jimenez, J. Bartroli, N. F. de Rooij and M. Koudelka-Hep, Anal. Chim. Acta, 1997, 351, 169-176.

106 J. Munoz, C. Jimenez, A. Bratov, J. Bartroli, S. Alegret and C. Dominguez, Biosens. Bioelectron., 1997, 12, 577-585.

107 O. A. Boubriak, A. P. Soldatkin, N. F. Staradub, A. K. Sandrovsky and A. K. El'skaya, Sens. Actuators, B, 1995, 26-27, 429-43.

108 A. Senillou, N. Jaffrezic-Renault, C. Martelet and S. Cosnier, Talanta, 1999, 50, 219-226.

109 A. Poghossian, M. Thust, P. Schroth, A. Steffen, H. Lüth and M. J. Schöning, Sens. Mater., 2001, 13, 207-223.

110 A. Poghossian, M. J. Schöning, P. Schroth, A. Simonis and H. Lüth, Sens. Actuators, B, 2001, 76, 519-526.

111 A. Poghossian, H. Lüth, J. W. Schultze and M. J. Schöning, Electrochim. Acta, 2001, 47, 243-249.

112 A. Poghossian, T. Yoshinobu, A. Simonis, H. Ecken, H. Lüth and M. J. Schöning, Sens. Actuators, B, 2001, 78, 237-242.

113 A. P. Soldatkin, D. V. Gorchkov, C. Martelet and N. JaffrezicRenault, Mater. Sci. Eng., 1997, C 5, 35-40.

114 J. Liu, L. Liang, G. Li, R. Han and K. Chen, Biosens. Bioelectron., 1998, 13, 1023-1028.

115 D. V. Gorchkov, A. P. Soldatkin, H. Maupas, C. Martelet and N. Jaffrezic-Renault, Anal. Chim. Acta, 1996, 331, 217-223.

116 F. Sevilla, T. Kullick and T. Scheper, Biosens. Bioelectron., 1994, 9, 275-281.
117 E. Tobias-Katona and M. Pecs, Sens. Actuators, B, 1995, 28, 17-20.

118 V. Volotovsky and N. Kim, Anal. Chim. Acta, 1998, 359, 143-148.

119 L. L. Chi, L. T. Yin, J. C. Chou, W. Y. Chung, T. P. Sun, K. P. Hsiung and S. K. Hsiung, Sens. Actuators, B, 2000, 71, 68-72.

120 N. Jaffrezic-Renault, Sensors, 2001, 1, 60-74.

121 L. Campanella, C. Colapicchioni, G. Favero, M. P. Sammartino and M. Tomassetti, Sens. Actuators, B, 1996, 33, 25-33.

122 A. K. Singh, J. V. Volponi, S. C. Carichner, K. Wally, A. L. Simonian, J. R. Wild and J. S. Schoeniger, Biosens. Bioelectron., 1999, 14, 715-722.

123 A. L. Simonian, J. K. Grimsley, A. W. Flounders, J. S. Schoeniger, T. C. Cheng, J. J. De Frank and J. R. Wild, Anal. Chim. Acta, 2001, 442, 15-23.

124 Y. I. Korpan, A. P. Soldatkin, M. V. Gonchar, A. A. Sibirny, T. D. Dibson and A. V. El'skaya, J. Chem. Technol. Biotechnol., 1997, 68, 209-213.

125 Y. I. Korpan, M. V. Gonchar, A. A. Sibirny, C. Martelet, A. V. El'skaya, T. D. Gibson and A. P. Soldatkin, Biosens. Bioelectron., 2000, 15, 77-83.

126 Y. Murakami, Y. Suzuki, K. Yokoyama and E. Tamiya, Denki Kagaku, 1996, 64, 1272-1273.

127 A. P. Soldatkin, D. V. Gorchkov, C. Martelet and N. JaffrezicRenault, Sens. Actuators, B, 1997, 43, 99-104.

128 W. Moritz, J. Szeponik, F. Listad, A. Friebe, S. Krause, R. Hintsche and F. Scheller, Sens. Actuators, B, 1992, 7, 497-500.

129 S. Kayashima, T. Arai, M. Noritake, N. Nagata, M. Kikuchi, N. Ito, Y. Matsumoto, A. Kaneyoshi, J. Kimura and T. Kuriyama, Clin. Chim. Acta, 1995, 240, 11-19.

130 N. Ito, A. Saito, S. Kayashima, J. Kimura, T. Kuriyama, N. Nagata, T. Arai and M. Kikuchi, Front. Med. Biol. Eng., 1995, 6, 269-280.

131 M. Zayats, A. B. Kharitonov, E. Katz, A. F. Bückmann and I. Willner, Biosens. Bioelectron., 2000, 15, 671-680.

132 A. B. Kharitonov, M. Zayats, L. Alfonta, E. Katz and I. Willner, Sens. Actuators, B, 2001, 76, 203-210.

133 B. H. van der Schoot, H. Voorthuyzen and P. Bergveld, Sens. Actuators, B, 1990, 1, 546-549.

134 J. R. Sandifer and J. J. Voycheck, Mikrochim. Acta, 1999, 131, 91-98.

135 C. D. James, R. C. Davis, L. Kam, H. G. Craighead, M. Isaacson, J. N. Turner and W. Shain, Langmuir, 1998, 14, 741-744.

136 R. E. G. van Hal, P. Bergveld and J. F. J. Engbersen, Sens. Mater., $1996,8,455-468$

137 E. Yacoub-George, H. Wolf, S. Koch and P. Woias, Sens. Actuators, $B, 1996,34,429-434$.

138 C. Colapicchioni, A. Barbaro, F. Porcelle and I. Giannini, Sens. Actuators, B, 1991, 4, 245-250.

139 N. F. Staradub, B. B. Dzantiev, V. M. Staradub and A. V. Zherdev, Anal. Chim. Acta, 2000, 424, 37-43.

140 T. Sekiguchi, M. Nakamura, M. Kato, K. Nishikawa, K. Hokari, T. Sugiyama and M. Asaka, Sens. Actuators, B, 2000, 67, 265-269.

141 H. Tsuruta, H. Yamada, Y. Motoyashiki, K. Oka, C. Okada and M. Nakamura, J. Immunol. Methods, 1995, 183, 221-229.

142 T. A. Sergeyeva, A. P. Soldatkin, A. E. Rachkov, M. I. Tereschenko, S. A. Piletski and A. V. El'skaya, Anal. Chim. Acta, 1999, 390, 73-81.

143 R. I. Stefan, J. F. van Staden and H. Y. Aboul-Enein, Fresenius' J. Anal. Chem., 2000, 366, 659-668.

144 A. L. Ghindilis, P. Abanasov, M. Wilkins and E. Wilkins, Biosens. Bioelectron., 1998, 13, 113-131.

145 P. Skladal, Electroanalysis, 1997, 9, 737-745.

146 R. B. M. Schasfoort, R. P. H. Kooyman, P. Bergveld and J. Greve, Biosens. Bioelectron., 1990, 5, 103-124.

147 R. B. M. Schasfoort, P. Bergveld, R. P. H. Kooyman and J. Greve, Anal. Chim. Acta, 1990, 238, 323-329.

148 P. Bergveld, Biosens. Bioelectron., 1991, 6, 55-72.

149 J. C. van Kerkhof, P. Bergveld and R. B. M. Schasfoort, Biosens. Bioelectron., 1995, 10, 269-282.

150 P. Bergveld, R. E. G. van Hal and J. C. T. Eijkel, Biosens. Bioelectron., 1995, 10, 405-414

151 J. Kruise, J. C. T. Eijkel and P. Bergveld, Sens. Actuators, B, 1997, 44, 297-303

152 W. Olthuis, P. Bergveld and J. Kruise, Electrochim. Acta, 1998, 43, 3483-3488.

153 S. Koch, P. Woias, E. Kudlich and B. Zimmerer, Sens. Actuators, B, 1996, 34, 289-294.

154 S. Koch, P. Woias, L. K. Meixner, S. Drost and H. Wolf, Biosens. Bioelectron., 1999, 14, 417-425.

155 J. Kruise, J. G. Rispens, P. Bergveld, F. J. B. Kremer, D. Starmans, J. R. Haak, J. Reijen and D. N. Reinhoudt, Sens. Actuators, B, 1992, 6, 101-105. 
156 A. B. Kharitonov, J. Wasserman, E. Katz and I. Willmer, J. Phys. Chem. B, 2001, 105, 4205-4213.

157 C. H. Mastrangelo, in Solid State Chemical and Biochemical Sensors, ed. P. Vincenzini and L. Dori, Techna, Faenza, 1999, pp. 465-476.

158 J. Wang, Nucleic Acids Res., 2000, 28, 3011-3016.

159 S. R. Mikkelsen, Electroanalysis, 1996, 8, 15-19.

160 M. Mascini, I. Palchetti and G. Marrazza, Fresenius' J. Anal. Chem., 2001, 369, 15-22.

161 M. Yang, M. E. McGovern and M. Thompson, Anal. Chim. Acta, 1997, 346, 259-275.

162 C. Berggren, P. Stalhandske, J. Brundell and G. Johnsson, Electroanalysis, 1999, 11, 156-160.

163 E. Souteyrand, J. P. Chauvet, V. Dugas and F. Bessueille, Appl. Surf. Sci., 2000, 164, 246-251.

164 E. Souteyrand, Analusis, 1999, 27, 639-646.

165 T. Sakurai and Y. Husimi, Anal. Chem., 1992, 64, 1996-1997.

166 H. Tsuruta, S. Matsui, T. Hatanaka, T. Namba, K. Miyamoto and M. Nakamura, J. Immunol. Methods, 1994, 176, 45-52.

167 H. Tsuruta, S. Matsui, K. Oka, T. Namba, M. Shinugu and M. Nakamura, J. Immunol. Methods, 1995, 180, 259-264.

168 J. P. Cloarec, J. R. Martin, C. Polychronakos, I. Lawrence, M. F. Lawrence and E. Souteyrand, Sens. Actuators, B, 1999, 58, 394-398.

169 E. Souteyrand, C. Chen, J. P. Cloarec, X. Nesme, P. Simonet, I. Navarro and J. R. Martin, Appl. Biochem. Biotechnol., 2000, 89, 195-207.

170 J. P. Cloarec, N. Deligianis, J. R. Martin, I. Lawrence, E. Souteyrand, C. Polychronakos and M. F. Lawrence, Biosens. Bioelectron., 2002, 17, 405-412.

171 H. Berney, J. West, E. Haefele, J. Alderman, W. Lane and J. K. Collins, Sens. Actuators, B, 2000, 68, 100-108.

172 P. A. E. Piunno, J. Watterson, C. C. Wast and U. J. Krull, Anal. Chim. Acta, 1999, 400, 73-89.

173 M. I. Pivadori, A. Merkoci and S. Alegret, Biosens. Bioelectron., 2001, 15, 291-303.

174 A. Vainrub and B. M. Pettitt, Chem. Phys. Lett., 2000, 323, $160-166$.

175 M. Bove, S. Martinoia, M. Grattarola and D. Ricci, Thin Solid Films, 1996, 285, 772-775.

176 B. Wolf, M. Brischwein, W. Baumann, R. Ehret and M. Kraus, Biosens. Bioelectron., 1998, 13, 501-509.

177 W. H. Baumann, M. Lehmann, A. Schwinde, R. Ehret, M. Brischwein and B. Wolf, Sens. Actuators, B, 1999, 55, 77-89.

178 L. Bousse, Sens. Actuators, B, 1996, 34, 270-275.

179 A. Offenhäusser and W. Knoll, Trends Biotechnol., 2001, 19, 62-66.

180 F. Hafner, Biosens. Bioelectron., 2000, 15, 149-158.

181 P. Bergveld, IEEE Trans. Biomed. Eng., 1972, 19, 342-351.

182 A. Fanigliulo, P. Accossato, M. Adami, M. Lanzi, S. Martinoia, M. Grattarola and C. Nicolini, Sens. Actuators, B, 1996, 32, 41-48.

183 D. Schubnell, M. Lehmann, W. Baumann, F. G. Rott, W. Wolf and C. F. Beck, Biosens. Bioelectron., 1999, 14, 465-472.

184 M. Lehmann, W. Baumann, M. Brischwein, R. Ehret, M. Kraus, A Schwinde, M. Bitzenhofer, I. Freund and B. Wolf, Biosens. Bioelectron., 2000, 15, 117-124.

185 R. Ehret, W. Baumann, M. Brischwein, M. Lehmann, T. Henning, I. Freund, S. Drechsler, U. Friedrich, M. L. Hubert, E. Motresen, A. Kob, H. Palzer, H. Grothe and B. Wolf, Fresenius' J. Anal. Chem., 2001, 369, 30-35.

186 B. Wolf, M. Brischwein, W. Baumann, R. Ehret, T. Henning, M. Lehmann and A. Schwinde, Tumor Biology, 1998, 19, 374-383.

187 M. Lehmann, W. Baumann, M. Brischwein, H. J. Gahle, I. Freund, R. Ehret, S. Drechsler, H. Palzer, M. Kleintges, U. Sieben and B. Wolf, Biosens. Bioelectron., 2001, 16, 195-203.

188 S. Martinoia, N. Rosso, M. Grattarola, L. Lorenzelli, B. Margesin and M. Zen, Biosens. Bioelectron., 2001, 16, 1043-1050.

189 L. Campanella, G. Favero, D. Mastrofini and M. Tomassetti, Sens. Actuators, B, 1997, 44, 279-285.
190 P. Bergveld, J. Wiersma and H. Meertens, IEEE Trans. Biomed. Eng., 1976, 23, 136-144.

191 S. Vassanelli and P. Fromherz, Appl. Phys. A, 1998, 66, 459-463.

192 C. Sprössler, M. Denyer, S. Britland, W. Knoll and A. Offenhäusser, Phys. Rev. E, 1999, 60, 2171-2176.

193 P. Fromherz and A. Stett, Phys. Rev. Lett., 1995, 75, 1670-1673.

194 A. Stett, B. Müller and P. Fromherz, Phys. Rev. E, 1997, 55, 1779-1782.

195 P. Fromherz, Phys. Rev. Lett., 1997, 78, 4131-4134.

196 S. Vassanelli and P. Fromherz, J. Neurosci., 1999, 19, 6767-6773.

197 M. Grattarolla and S. Martinoia, IEEE Trans. Biomed. Eng., 1993, 40, 35-41.

198 B. Straub, E. Meyer and P. Fromherz, Nature Biotechnol., 2001, 19, 121-124.

199 V. Kiessling, B. Müller and P. Fromherz, Langmuir, 2000, 16, 3517-3521.

200 A. Offenhäusser, J. Rühe and W. Knoll, J. Vac. Sci. Technol., A, 1995, 13, 2606-2612.

201 S. Turner, L. Kam, M. Isaacson, H. G. Craighead, W. Shain and J. Turner, J. Vac. Sci. Technol., B, 1997, 15, 2848-2854.

202 E. Richter, G. Fuhr, T. Müller, S. Shirley, S. Rogaschewski, K. Reimer and C. Dell, J. Mater. Sci.: Mater. Med., 1966, 7, 85-97.

203 P. Heiduschka, I. Romann, H. Ecken, M. Schöning, W. Schuhmann and S. Thanos, Electrochim. Acta, 2001, 47, 299-307.

204 A. Offenhäusser, C. Sprössler, M. Matsuzawa and W. Knoll, Biosens. Bioelectron., 1997, 12, 819-826.

205 C. Sprössler, D. Richter, M. Denyer and A. Offenhäusser, Biosens. Bioelectron., 1998, 13, 613-618.

206 S. Ingebrandt, C. K. Yeung, M. Krause and A. Offenhäusser, Biosens Bioelectron., 2001, 16, 565-570.

207 C. K. Yeung, S. Ingebrandt, M. Krause, A. Offenhäusser and W. Knoll, J. Pharmacol. Toxicol. Methods, 2001, 45, 207-214.

208 M. Scholl, C. Sprössler, M. Denyer, M. Krause, K. Nakajima, A. Maelicke, W. Knoll and A. Offenhäusser, J. Neurosci. Methods, 2000, 104, 65-75.

209 C. Sprössler, M. Scholl, M. C. Denyer, M. Krause, K. Nakajima, A. Maelicke, W. Knoll and A. Offenhäusser, Synth. Met., 2001, 117, 281-283.

210 J. C. Chang, G. J. Brewer and B. C. Wheeler, Biosens. Bioelectron., 2001, 16, 527-533.

211 S. Belli and G. Rechnitz, Anal. Lett., 1986, 19, 403-405.

212 M. J. Schöning, S. Schütz, P. Schroth, B. Weissbecker, A. Steffen, P Kordos, H. E. Hummel and H. Lüth, Sens. Actuators, B, 1998, 47, 235-238.

213 P. Schroth, M. J. Schöning, S. Schütz, Ü. Malkoc, A. Steffen, M. Marso, H. E. Hummel, P. Kordos and H. Lüth, Electrochim. Acta, 1999, 44, 3821-3826.

214 P. Schroth, M. J. Schöning, P. Kordos, H. Lüth, S. Schütz, B. Weissbecker and H. E. Hummel, Biosens. Bioelectron., 1999, 14, 303-308.

215 M. J. Schöning, P. Schroth and S. Schütz, Electroanalysis, 2000, 12, 645-652.

216 M. J. Schöning and H. Lüth, Phys. Stat. Sol. A, 2001, 185, 65-77.

217 P. Schroth, H. Lüth, H. E. Hummel, S. Schütz and M. J. Schöning, Electrochim. Acta, 2001, 47, 293-297.

218 P. Schroth, B. Weissbecker, S. Schütz, H. Ecken, T. Yoshinobu, H. Lüth and M. J. Schöning, Biocybern. Biomed. Eng., 2001, 21, 27-42.

219 P. Schroth, M. J. Schöning, H. Lüth, B. Weissbecker, H. E. Hummel and S. Schütz, Sens. Actuators, B, 2001, 78, 1-5.

220 S. Schütz, M. J. Schöning, P. Schroth, Ü. Malkoc, B. Weissbecker, P. Kordos, H. Lüth and H. E. Hummel, Sens. Actuators, B, 2000, 65, 291-295.

221 M. J. Huotari, Sens. Actuators, B, 2000, 71, 212-222.

222 M. J. Schöning, A. Poghossian, J. W. Schultze and H. Lüth, Proc. SPIE, 2002, 4576, 149-159. 